\title{
Indian Ocean Capacitor Effect on Indo-Western Pacific Climate during the Summer following EI Niño
}

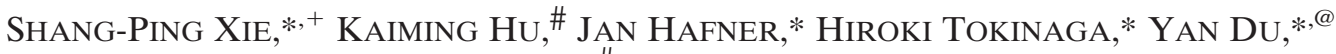 \\ GANG HUANG, ${ }^{\#}$ AND TAKEAKI SAMPE* \\ * International Pacific Research Center, University of Hawaii at Manoa, Honolulu, Hawaii \\ ${ }^{+}$Department of Meteorology, University of Hawaii at Manoa, Honolulu, Hawaii \\ \# Institute of Atmospheric Physics, Chinese Academy of Sciences, Beijing, China \\ @ South China Sea Institute of Oceanology, Chinese Academy of Sciences, Guangzhou, China
}

(Manuscript received 24 March 2008, in final form 7 July 2008)

\begin{abstract}
Significant climate anomalies persist through the summer (June-August) after El Niño dissipates in spring over the equatorial Pacific. They include the tropical Indian Ocean (TIO) sea surface temperature (SST) warming, increased tropical tropospheric temperature, an anomalous anticyclone over the subtropical northwest Pacific, and increased mei-yu-baiu rainfall over East Asia. The cause of these lingering El Niño effects during summer is investigated using observations and an atmospheric general circulation model (GCM). The results herein indicate that the TIO warming acts like a capacitor anchoring atmospheric anomalies over the Indo-western Pacific Oceans. It causes tropospheric temperature to increase by a moistadiabatic adjustment in deep convection, emanating a baroclinic Kelvin wave into the Pacific. In the northwest Pacific, this equatorial Kelvin wave induces northeasterly surface wind anomalies, and the resultant divergence in the subtropics triggers suppressed convection and the anomalous anticyclone. The GCM results support this Kelvin wave-induced Ekman divergence mechanism. In response to a prescribed SST increase over the TIO, the model simulates the Kelvin wave with low pressure on the equator as well as suppressed convection and the anomalous anticyclone over the subtropical northwest Pacific. An additional experiment further indicates that the north Indian Ocean warming is most important for the Kelvin wave and northwest Pacific anticyclone, a result corroborated by observations.

These results have important implications for the predictability of Indo-western Pacific summer climate: the spatial distribution and magnitude of the TIO warming, rather than simply whether there is an El Niño in the preceding winter, affect summer climate anomalies over the Indo-western Pacific and East Asia.
\end{abstract}

\section{Introduction}

El Niño-Southern Oscillation (ENSO) is the dominant mode of climate variability on instrumental records. Typically, El Niño develops during boreal summer, peaks during early winter, and decays the following spring (Fig. 1). Hereafter, seasons refer to those for the Northern Hemisphere. We denote the ENSO-developing year as year 0 and the following year as year 1. Thus, the summer [June-August (JJA)] of the ENSO-developing year is symbolized as JJA(0), while the summer of the following year as JJA(1). By JJA(1), eastern Pacific sea surface temperature (SST) returns

Corresponding author address: Shang-Ping Xie, IPRC, SOEST, University of Hawaii at Manoa, Honolulu, HI 96822.

E-mail: xie@hawaii.edu either to or slightly below normal. By shifting tropical convection, El Niño excites atmospheric teleconnection into other tropical oceans and the extratropical PacificNorth America (PNA) sector. The so-called atmospheric bridge effect in the tropics is manifested in the delayed spring warming of the Indian (Klein et al. 1999) and North Atlantic (Enfield and Mayer 1997) Oceans. Because of large SST anomalies in the tropics and an effective tropics-to-midlatitude waveguide, the PNA teleconnection is most pronounced during the peak phase of El Niño, providing winter climate predictability for North America (Trenberth et al. 1998; Alexander et al. 2002).

Pronounced ENSO-related anomalies linger mysteriously during JJA(1) after eastern Pacific SST anomalies have dissipated. Chinese researchers have long suggested that during the summer, following El Niño, 


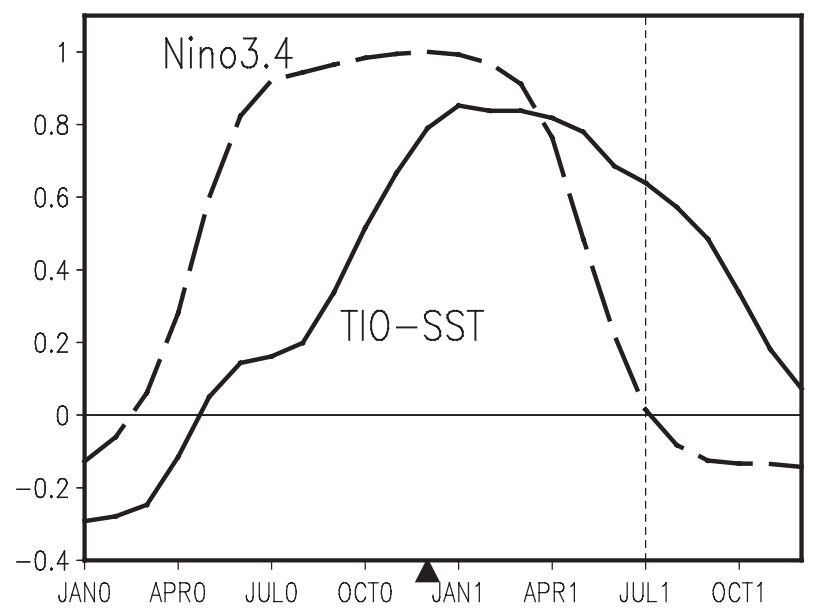

FIG. 1. Correlation of tropical Indian Ocean $\left(20^{\circ} \mathrm{S}-20^{\circ} \mathrm{N}, 40^{\circ}-\right.$ $\left.100^{\circ} \mathrm{E}\right) \mathrm{SST}$ (solid) with the Niño-3.4 $\left(5^{\circ} \mathrm{S}-5^{\circ} \mathrm{N}, 170^{\circ}-120^{\circ} \mathrm{W}\right) \mathrm{SST}$ index for November(0)-December(0)-January(1). Numerals in parentheses denote years relative to El Niño: 0 for its developing and 1 for decay year. The dashed curve is the Niño-3.4 SST autocorrelation as a function of lag. The black triangle denotes December(0), the peak phase of ENSO.

pronounced precipitation anomalies tend to take place near the Yangtze River (Fu and Teng 1988; Huang and Wu 1989; Huang et al. 2004), causing major floods there as in 1954 and 1998 summers. Over the northwest (NW) Pacific, climatic anomalies can be even larger and more robust during the summer following than preceding the El Niño peak, despite much weaker SST anomalies in the eastern Pacific.

Figure 2 illustrates some of the mysterious JJA(1) anomalies based on surface observations over the NW Pacific, as represented by correlation with the Niño-3.4 $\left(5^{\circ} \mathrm{S}-5^{\circ} \mathrm{N}, 120^{\circ}-170^{\circ} \mathrm{W}\right) \mathrm{SST}$ index at its peak phase [November-December (ND)(0)-January(J)(1), hereafter $\mathrm{NDJ}(0)]$. At Guam $\left(13.5^{\circ} \mathrm{N}, 145^{\circ} \mathrm{E}\right)$, precipitation is not significantly correlated with ENSO during its developing phase. A negative correlation begins to develop around December-February (DJF)(1), peaks during February-March(1), and persists through JJA(1) (Fig. 2a, solid) when the eastern Pacific SST index already turns slightly negative. Consistent with the rainfall correlation, sea level pressure (SLP) in the broad subtropical NW Pacific begins to develop strong positive correlation with El Niño at $\operatorname{NDJ}(0)$, which peaks during the spring (Wang et al. 2003). This correlation decays thereafter but remains significant at the $95 \%$ level through JJA(1) (Fig. 2b). The South China Sea (SCS) is the third example, displaying pronounced warming twice at the peak phase of El Niño (Liu et al. 2004) and July-September (JAS)(1) (Xie et al. 2003; Wang et al. 2006), respectively (Fig. 2c). The summer warming is associated with a reduction in the southwest monsoon and ocean upwelling it induces. The delayed ENSO effects extend to the midlatitude atmosphere. Precipitation at Hachijo Island $\left(33.1^{\circ} \mathrm{N}, 139.8^{\circ} \mathrm{E}\right)$ south of Tokyo, Japan, displays two peaks in correlation with ENSO (Fig. 2a, dashed): one in $\operatorname{DJF}(1)$ and one in JJA(1), both of which are well above the $95 \%$ significance level. The summer correlation at Hachijo is of the opposite sign to that at Guam, linked by a meridional teleconnection pattern (Nitta 1987). Our last example is Ishigaki Island $\left(24.3^{\circ} \mathrm{N}, 124.2^{\circ} \mathrm{E}\right)$, Japan, where sea level shows a significant positive correlation at a very long lag, during November-December(1) (Fig. 2d). Such prolonged ENSO effects during JJA(1) are the focus of the present study.

Over the subtropical NW Pacific, an anomalous high pressure system with an anticyclonic surface circulation begins to appear at the ENSO mature phase (winter) and develops into maximum intensity during spring (Harrison and Larkin 1996; Wang et al. 2000, 2003), broadly consistent with Fig. $2 b$. At its peak phase (spring), this surface high is roughly collocated with negative SST anomalies, suggestive of a local oceanatmosphere interaction (Wang et al. 2000; Lau and Nath 2003). Wang et al. (2000) propose that SST-induced anticyclonic circulation, superimposed on the spring northeast trades, acts to reinforce the initial SST anomalies via surface evaporation and wind stirring. Their mechanism is a variant of wind-evaporation-SST (WES) feedback that emphasizes the role of meridional wind instead of zonal wind in the previous literature (Xie 2004). The anticyclonic anomaly persists into JJA(1) as corroborated by in situ observations (Fig. 2), but the local SST feedback does not seem to persist through summer. A local feedback requires positive correlation between SST and precipitation but observations indicate that this correlation is weak or even negative during summer (Wang et al. 2005). Results from the present study show that atmospheric anomalies during JJA(1) over the NW Pacific are forced not by local SST, but remotely by Indian Ocean SST.

The tropical Indian Ocean (TIO) warms up following the El Niño peak because of the downwelling ocean Rossby waves in the southwestern basin (Xie et al. 2002; Huang and Kinter 2002) and heat flux changes elsewhere (Klein et al. 1999; Tokinaga and Tanimoto 2004). See Schott et al. (2008) for a recent review of the TIO response to ENSO. During the El Niño mature phase, precipitation decreases over the TIO despite this basinwide warming, leading to a notion that the TIO warming is largely a passive response to ENSO teleconnection without much climatic influences. Countering this notion, however, recent modeling studies suggest that the TIO warming is partially responsible for the formation of the 
(a) Guam \& Hachijojima rain

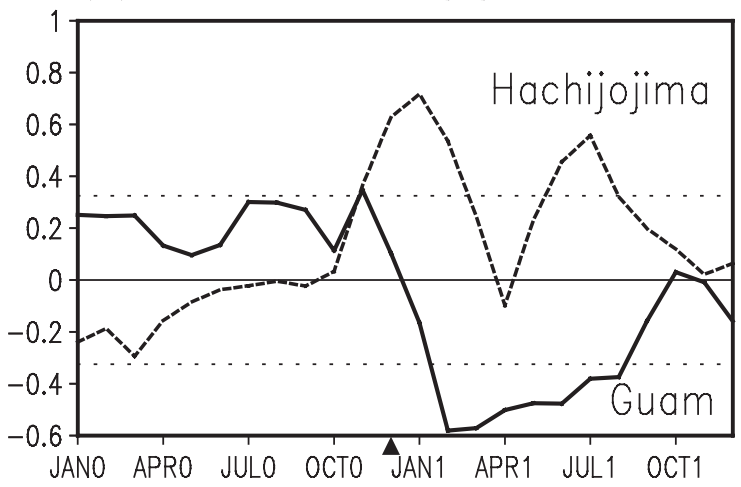

(c) SCS SST

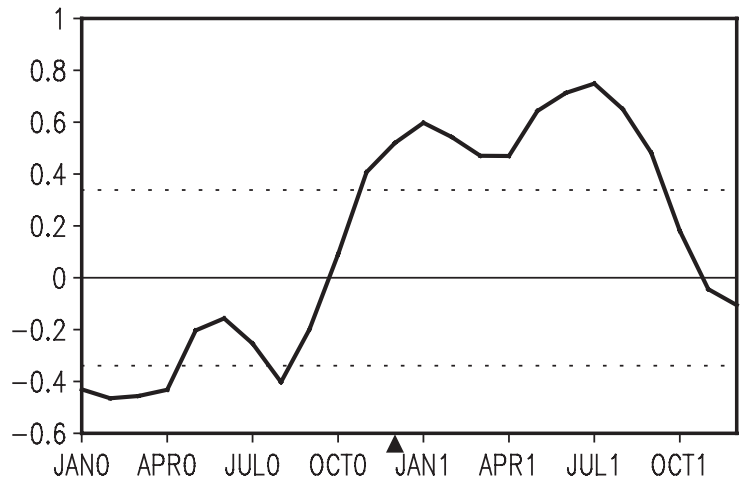

(b) NWP SLP \& $\delta U$

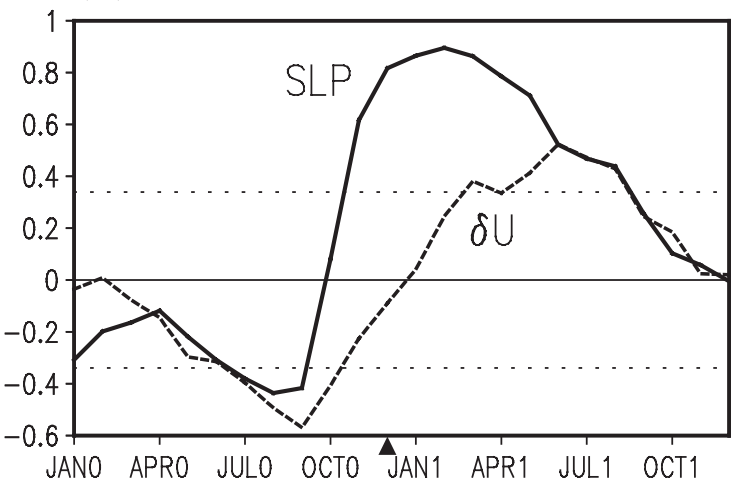

(d) SLH at Ishigaki

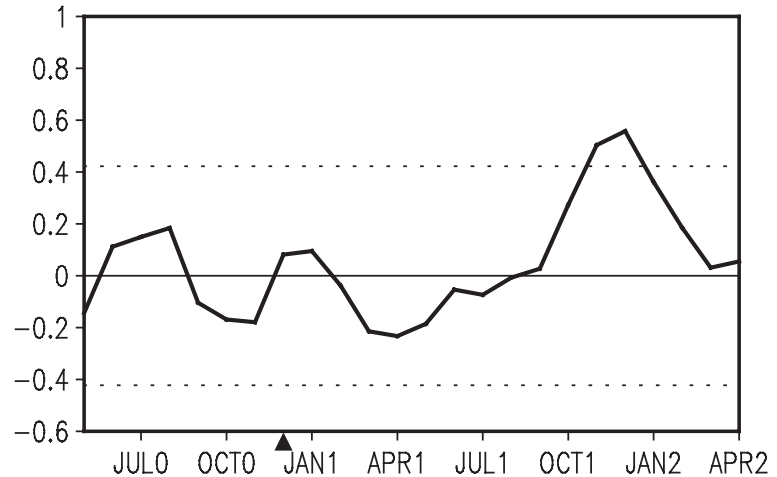

FIG. 2. Correlation with the NDJ(0) Niño-3.4 SST index: (a) rainfall at Guam and Hachijo Islands; (b) subtropical NW Pacific SLP $\left(10^{\circ}-25^{\circ} \mathrm{N}, 130^{\circ}-170^{\circ} \mathrm{E}\right)$, and surface wind vorticity defined as $\left(27^{\circ}-33^{\circ} \mathrm{N}\right)$ minus $\left(11^{\circ}-15^{\circ} \mathrm{N}\right)$ zonal wind difference averaged in $120^{\circ}-150^{\circ} \mathrm{E}$; (c) SCS SST $\left(5^{\circ}-15^{\circ} \mathrm{N}, 110^{\circ}-125^{\circ} \mathrm{E}\right)$; and (d) sea level height at Ishigaki Island. (b) and (c) Based on ICOADS. Dotted lines indicate the $95 \%$ significance level, which varies with the data record length. (In (a), the significance level is 0.44 for the shorter Hachijo record.) The black triangle denotes December(0), the peak phase of ENSO.

NW Pacific anticyclone anomaly from winter to spring (Watanabe and Jin 2003; Annamalai et al. 2005), and its persistence into JJA(1) (Yang et al. 2007). These results form the following capacitor hypothesis (Yang et al. 2007): El Niño teleconnection causes TIO SST to increase like a battery charging a capacitor; the TIO warming persists through the summer [JJA(1)], and exerts its climatic influences on surrounding regions after the El Niño decay, like a discharging capacitor. Early studies based on correlation (Wu et al. 1995) and idealized general circulation model (GCM) experiments (Wu and Liu 1995) have hinted at TIO SST effects on East Asian-western Pacific climate in summer. More recently, Yoo et al. (2006) note that spring TIO SST is a good predictor for the summer NW Pacific anticyclone. While they do not clarify what maintains this relationship between spring SST and summer atmospheric anomalies, Fig. 1 shows that the TIO SST persistence is the likely cause. Ohba and Ueda (2006) suggest that SST gradients between the North Indian and NW Pacific Oceans are important for June precipitation variability east of the Philippines.
While the persistence of the NW Pacific anticyclone through summer may indeed be due to the TIO capacitor effect, the mechanism by which TIO SST affects the subtropical NW Pacific remains unclear.

The TIO capacitor effect may go beyond the subtropical NW Pacific surface circulation. Tropospheric temperature is known to increase over the tropics following El Niño (Yulaeva and Wallace 1994; Sobel et al. 2002), and the tropospheric warming lasts much longer than El Niño itself. Atmospheric GCM experiments show that much of the persistence in zonal-mean tropospheric temperature increase is not due to eastern Pacific SST, but to the SST warming over the tropical Indian and Atlantic Oceans (Kumar and Hoerling 2003; Lau et al. 2005). It is unclear whether and how the lingering tropospheric warming is related to surface anomalies, such as the subtropical NW Pacific anticyclone.

The present study examines robust, ENSO-induced climatic anomalies during JJA(1) when SST anomalies have mostly vanished over the equatorial Pacific. They include the TIO warming, NW Pacific anticyclone, 
and tropospheric warming. As reviewed briefly above, these anomalies have previously been studied somewhat in isolation. We note that most literature on the NW Pacific anticyclone deal with its formation and development from winter to spring (Wang et al. 2000, 2003; Watanabe and Jin 2003; Annamalai et al. 2005), but few focus on its maintenance for JJA(1) (Yang et al. 2007). Summer is the rainy season for East Asia when precipitation variability has huge socioeconomic impacts. The present study attempts a synthesis to reveal relationships among and mechanisms for these anomalies by tracking ENSO correlation into JJA(1). Specific questions of interest include the following: What maintains the robust precipitation and circulation anomalies over the NW Pacific? Is there evidence for remote influences of the TIO on the NW Pacific; what about local SST effect? Is the long-lasting tropospheric warming in any way related to surface anticyclone over the NW Pacific? Observational diagnostics are the main approach but numerical modeling is also used as necessary to test hypotheses.

In the following, section 2 describes the datasets and atmospheric GCM. Section 3 presents observational diagnosis, discusses the ENSO-induced anomalies during JJA(1) in the global tropics and over the Indo-western Pacific region, and tests the local SST and TIO capacitor hypotheses. Section 4 examines atmospheric anomalies in response to the TIO warming in models. Section 5 is a summary and discusses broad implications.

\section{Methods}

\section{a. Observational data}

We use the Hadley Centre Global Sea Surface Temperature (HadSST) dataset (Rayner et al. 2006), the Center for Climate Prediction (CPC) Merged Analysis of Precipitation (CMAP; Xie and Arkin 1996), and the National Centers for Environmental Prediction-National Center for Atmospheric Research (NCEP-NCAR) atmospheric reanalysis (Kalnay et al. 1996), originally on $1^{\circ}$, $2.5^{\circ}$, and $2.5^{\circ}$ grids, respectively. We have regridded these datasets onto a common $2.5^{\circ}$ latitude $\times 10^{\circ}$ longitude grid for a 29-yr period from 1979 to 2007 (limited by CMAP's satellite rainfall estimates). All of the features to be discussed have large zonal scales, and the coarse zonal grid spacing is to help suppress small-scale variability.

We complement the above data-assimilated/statistically interpolated datasets with ship observations in the International Comprehensive Ocean-Atmospheric Data Set (ICOADS; Worley et al. 2005), originally on a $2^{\circ}$ grid. Grid points without at least one observation for a given month are flagged as missing. No additional interpolation is made. We regrid ICOADS onto the same $2.5^{\circ}$ latitude $\times 10^{\circ}$ longitude grid, and limit our analysis to after 1950, when observations are relatively abundant.

To extend the precipitation record back beyond the CMAP period, monthly observations at Guam are used to track rainfall over the subtropical and midlatitude NW Pacific, respectively. We average data at five stations to form an island-mean precipitation series, which runs nearly continuously from 1945 . A different method by normalizing data at each station with its standard deviation yields a similar island-mean series. Observations at Hachijo Island for a shorter period (1980-2007) are used to monitor rainfall in the midlatitude NW Pacific. Monthly-mean sea level height data (19692007) at Ishigaki Island are obtained from the University of Hawaii Sea Level Center.

The present study focuses on interannual variability associated with ENSO. To reduce the effect of pronounced intraseasonal variability over the Indo-western Pacific Oceans, we perform a 3-month running average. A 9-yr running mean is then applied (separately for each calendar month) to remove decadal and longer variations, which are significant over the tropical Indo-Pacific Oceans (Deser et al. 2004; Du and Xie 2008). We use SST averaged over the eastern equatorial Pacific (Niño-3.4: $5^{\circ} \mathrm{S}-5^{\circ} \mathrm{N}, 120^{\circ}-170^{\circ} \mathrm{W}$ ) to track ENSO, which is referred to as the ENSO index. Typical decorrelation time for such bandpass-filtered time series is slightly more than half a year (Fig. 1). We estimate the total degree of freedom as (analysis period in years)/1.5. For a $29-y r$ time series, a correlation of 0.43 reaches the $95 \%$ significance level based on $t$ test.

\section{b. $G C M$}

The atmospheric GCM used is the ECHAM5, the latest Hamburg version of the European Centre for Medium-Range Weather Forecasts (ECMWF) model. A detail description of ECHAM5 is given by Roeckner et al. (2003). ECHAM5 employs a spectral dynamic core. We use a version with triangular truncation at zonal wavenumber 63 (T63; equivalent to $1.9^{\circ}$ horizontal resolution) and 19 sigma levels in the vertical.

The model is forced with the observed monthly climatology of SST and sea ice. We analyze a 20 -yr period of the control (CTL) simulation. We carry out two additional experiments. In the TIO run, we add $1^{\circ} \mathrm{C}$ SST over the TIO $\left(20^{\circ} \mathrm{S}-20^{\circ} \mathrm{N}, 40^{\circ}-110^{\circ} \mathrm{E}\right)$. In the other experiment, the same SST anomalies are imposed on the South Indian Ocean $\left(\mathrm{SIO} ; 20^{\circ} \mathrm{S}-0^{\circ}, 40^{\circ}-110^{\circ} \mathrm{E}\right)$. Experiments with a more realistic $0.5^{\circ} \mathrm{C} \mathrm{SST}$ anomaly yield similar results. In both TIO and SIO runs, the SST 


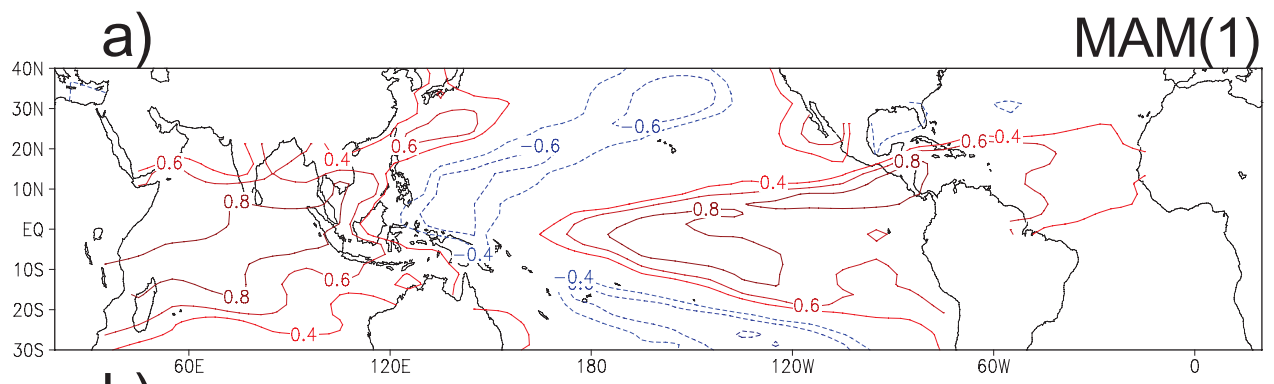

b)
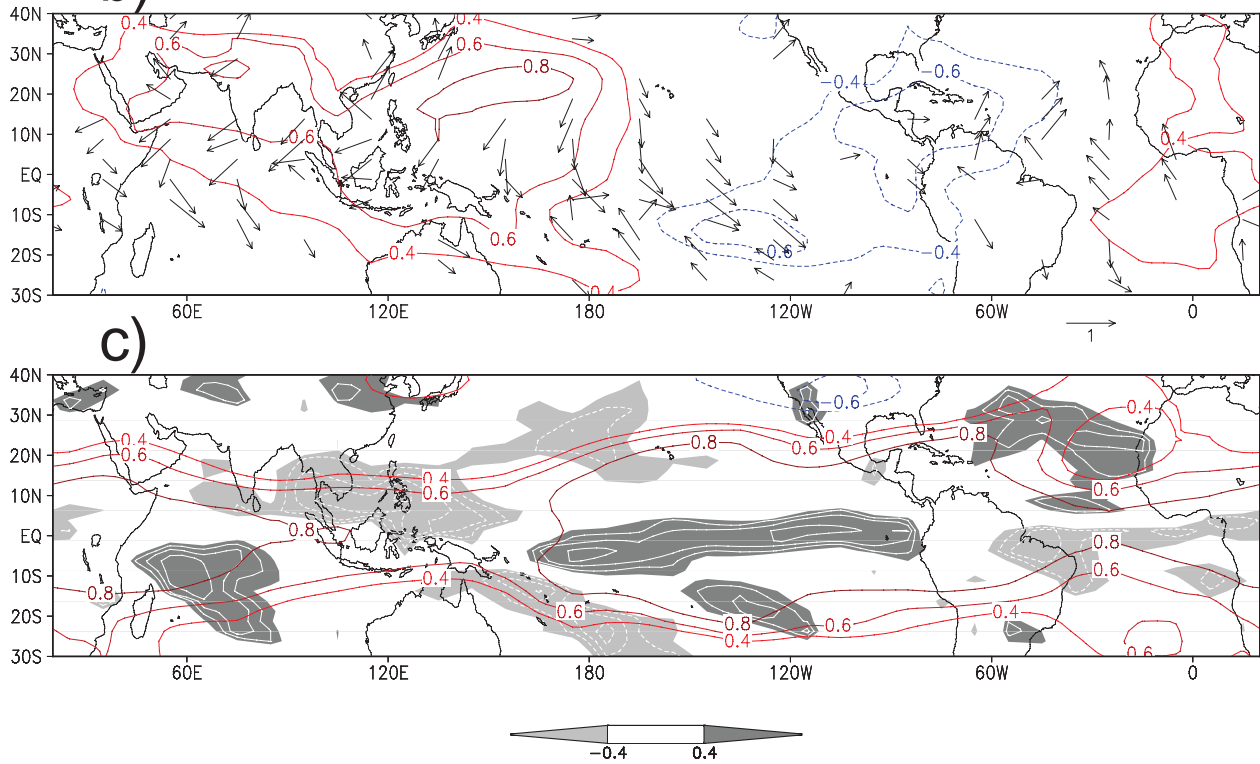

FIG. 3. MAM(1) correlation with the NDJ(0) Niño-3.4 SST index: (a) SST, (b) SLP (contours) and surface wind velocity, and (c) precipitation (gray shade and white contours at intervals of 0.1 ) and tropospheric temperature (contours).

anomalies are kept constant in time and the model is integrated for $20 \mathrm{yr}$. Thus, the experiments are equivalent to 20-member ensemble runs.

\section{Observational analysis}

This section examines spatiotemporal variations in ENSO correlation to infer the mechanisms for atmospheric anomalies.

\section{a. $M A M(1)$}

During March-May (MAM)(1), El Niño begins to decay but large positive anomalies of SST and precipitation remain in the eastern equatorial Pacific (Fig. 3). The westerly wind anomalies near the international date line are displaced south of the equator, rendering them ineffective to sustain the Bjerknes feedback and El Niño (Vecchi and Harrison 2006; Lengaigne et al. 2006). Precipitation decreases over the off-equatorial western Pacific, with a broad high pressure anomaly over the NW Pacific. The anomalous winds there intensify the prevailing northeast trades, contributing to the SST cooling (Wang et al. 2000). The upwelling Rossby waves in the ocean may also be a factor for the surface cooling (Wang et al. 1999).

Positive SST anomalies cover the entire TIO, with the maximum $(>0.8)$ over the tropical southwest Indian Ocean (SWIO), a signature of the downwelling Rossby waves over the shallow thermocline dome (Murtugudde and Busalacchi 1999; Behera et al. 2000; Xie et al. 2002; Huang and Kinter 2002). While the SST anomalies are more or less symmetrical, precipitation anomalies are nearly antisymmetric about the equator, positive over the SWIO, and negative over the eastern north Indian Ocean (NIO). Surface winds show a $\mathrm{C}$-shaped pattern typical of the response to antisymmetric heating, northeasterly north and northwesterly south of the equator. Kawamura et al. (2001) and Wu et al. (2008) suggest that this antisymmetric atmospheric pattern is due to be the WES feedback 


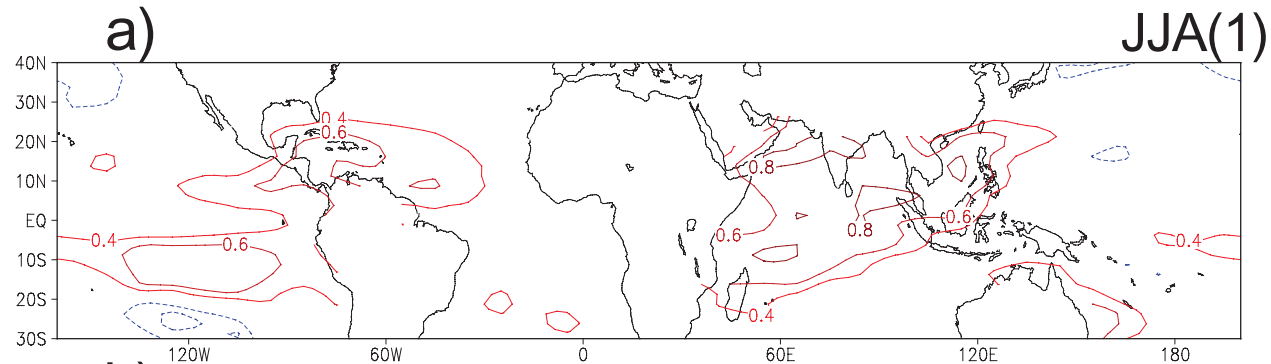

b)

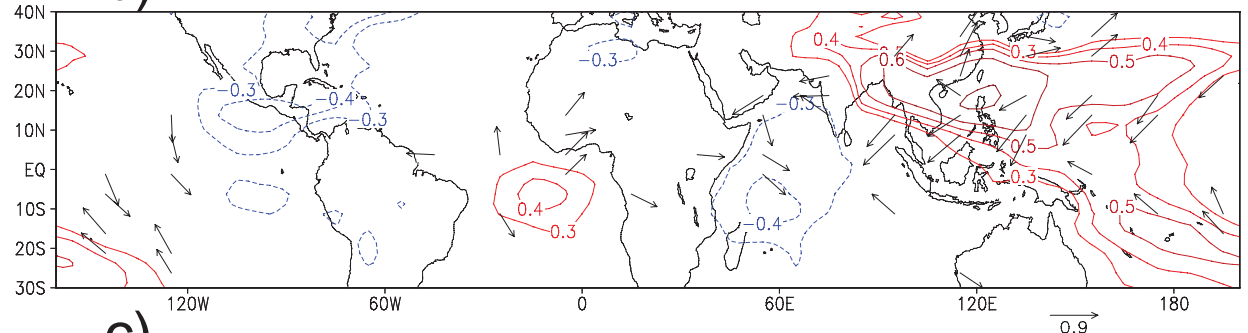

c)

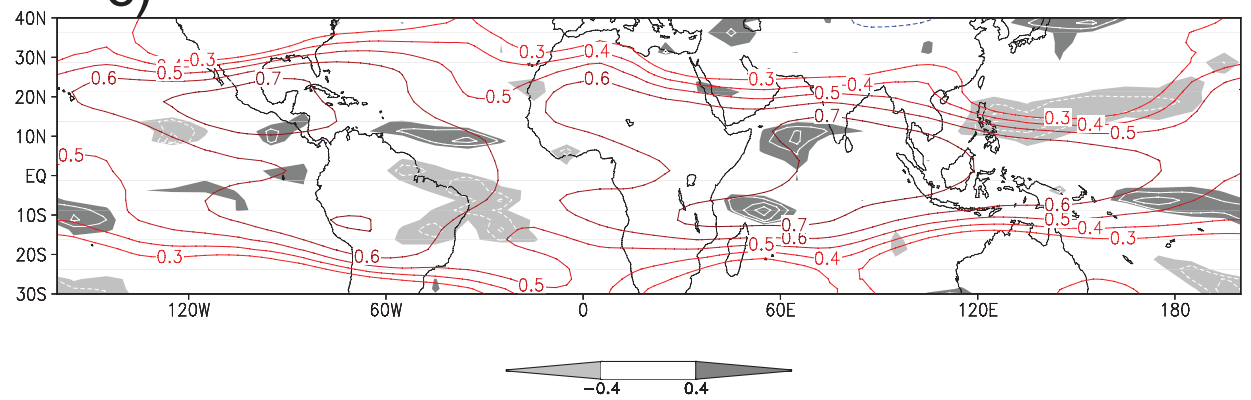

FIG. 4. Same for Fig. 3, except for JJA(1).

within the TIO. The northeasterly anomalies, in particular, help sustain the NIO warming through summer after the onset of the southwest monsoon in May (Du et al. 2009).

The free troposphere warms up along the entire equatorial belt, with tropospheric temperature correlation above 0.8 everywhere except over the western $\mathrm{Pa}$ cific (minimum $\sim 0.5^{\circ}$ at $160^{\circ} \mathrm{E}$ ). The correlation features an off-equatorial maximum on either side of the equator over the central/eastern Pacific and an equatorial maximum to the east, reminiscent of the MatsunoGill pattern (Matsuno 1966; Gill 1980) anchored by the eastern Pacific warming. This tropical-wide tropospheric warming takes place despite the tropical-mean precipitation anomaly being nearly zero, supporting the idea that deep convection adjusts tropospheric temperature to a moist-adiabatic profile over the warming eastern Pacific, spreading the tropospheric warming throughout the tropics via fast equatorial waves $(\mathrm{Su}$ et al. 2001; Chiang and Sobel 2002). El Niño-induced tropospheric warming has been proposed to cause SST to increase over other tropical oceans that support deep convection (Chiang and Sobel 2002; Chiang and Lintner 2005).

\section{b. $J J A(1)$}

Figure 4 shows JJA(1) correlations with the NDJ(0) ENSO index. SST anomalies vanish along the equator across the Pacific while SST correlation remains strong and exceeds 0.6 over much of the TIO. In contrast to MAM(1), when the decaying El Niño remains the major forcing for atmospheric anomalies, strong atmospheric correlations with coherent large-scale structure shift to the TIO and neighboring NW Pacific. The strongest atmospheric anomalies at the surface are located over the NW Pacific, including decreased rainfall and increased SLP. An anomalous anticyclone develops there, with northeasterly anomalies from the Bay of Bengal to the international date line. This summer anticyclone has been noted in previous studies (e.g., Wang et al. 2003) and the resultant weakening of the southwesterly monsoon wind causes a pronounced warming over the SCS (Xie et al. 2003; Wang et al. 2006). SST correlation is weakly negative but statistically marginal over the 


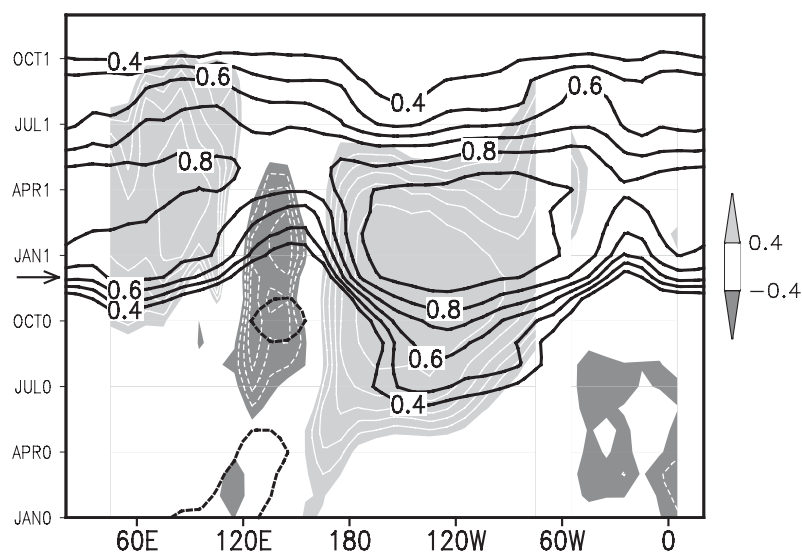

FIG. 5. Longitude-time section of correlation with the NDJ(0) Niño-3.4 index: SST (light shade $>0.4$; dark $<-0.4$; white contours at intervals of 0.1 ), and tropospheric temperature (black contours) on the equator. The black arrow denotes December(0), the peak phase of ENSO.

eastern half of the NW Pacific anticyclone (maximum correlation $r_{\max } \sim-0.4$ ), suggesting that local SST is not the main anchor for the decreased precipitation and increased SLP there. (More analysis of the SST correlation will be presented in section 3c.) This anticyclone is the most significant surface atmospheric anomaly during JJA(1) $\left(r_{\max } \sim 0.7\right)$ that originates from ENSO, while the TIO warming is the most significant major SST anomaly $\left(r_{\max } \sim 0.8\right)$, implying that the latter is the cause of the former. An empirical orthogonal function (EOF) analysis confirms this conclusion (see the appendix).

Tropospheric temperature displays a Matsuno-Gill pattern that is consistent with a localized heating in the TIO, with a Kelvin wave-like wedge penetrating into the western Pacific on the equator and Rossby wavelike, off-equatorial maxima over the western Indian Ocean to Africa. Tropical convection adjusts tropospheric temperature close to a moist-adiabatic profile, consistent with the equivalent potential temperature $(\theta \mathrm{e})$ in the planetary boundary layer (Emanuel et al. 1997). Thus, an SST increase over a convective region acts to warm the tropospheric column. The spatial pattern of tropospheric temperature anomalies (Figs. $3 \mathrm{c}, 4 \mathrm{c})$ appears to support this moist-adiabatic adjustment to ocean warming. Figure 5 shows tropospheric temperature correlation with the NDJ(0) ENSO index in the tropical Pacific and TIO, along with the SST correlation. Over the tropical Pacific, the troposphere begins to warm up soon after the development of El Niño. The tropospheric warming there reaches the maximum about a season after the El Niño peak and decays rapidly after April(1), falling below the 95\% significance level by July(1). Over the TIO, on the other hand, tropospheric warming commences quite late, developing rapidly in November(0) and reaching the peak in April(1). It persists at high correlation until August(1), and then decays rapidly with the TIO SST warming.

SST correlation falls to near zero on the equator (as the thermocline begins to shoal), but significant SST warming remains on either side of the equator in the eastern Pacific during JJA(1) (Fig. 4a). The southern SST warming does not have much of a signature in SLP because the mean SST is too cold for deep convection (Figs. 4b,c). North of the equator, by contrast, the SST warming over the far eastern Pacific warm pool and Caribbean Sea induces weak negative SLP anomalies and appears to reinvigorate the off-equatorial tropospheric warming. Because of the great geographical distance, it is unlikely that the lingering eastern Pacific SST anomalies north of the equator are the main cause of the NW Pacific anticyclone.

\section{c. Kelvin wave-induced divergence off the equator}

Precipitation correlation is weakly positive over the warm TIO, but not well organized in space. Restoring tropospheric temperature toward a moist-adiabatic profile, Su and Neelin (2003) show that their model simulates tropospheric temperature and precipitation anomalies during the developing and mature phases of El Niño. They report that the precipitation response is rather complicated and not necessarily correlated with local SST.

Given weak local SST correlation, the robust NW Pacific anticyclone at the surface is mysterious. We propose a mechanism for the TIO to force this surface anticyclone remotely. The moist-adiabatic adjustment provides a mechanism that couples SST and tropospheric temperature over the warm TIO (Emanuel et al. 1997; Neelin and Su 2005). Via this coupling, the TIO warming forces a warm equatorial Kelvin wave to the east. Figure 6 superimposes tropospheric temperature and surface wind correlations with the $\operatorname{NDJ}(0)$ ENSO index. Surface friction drives northeasterly winds onto the equatorial low pressure in the baroclinic Kelvin wave, inducing surface divergence and suppressing deep convection in the subtropical NW Pacific.

The circulation-convection feedback is important to amplify this Kelvin wave-induced Ekman divergence (WIED). While the Kelvin wave in the free troposphere is nearly symmetric about the equator, the response of convective and surface anomalies clearly favors the summer hemisphere (Fig. 6), where convective feedback is strong with high SST and precipitation in the mean. The negative rainfall anomalies 


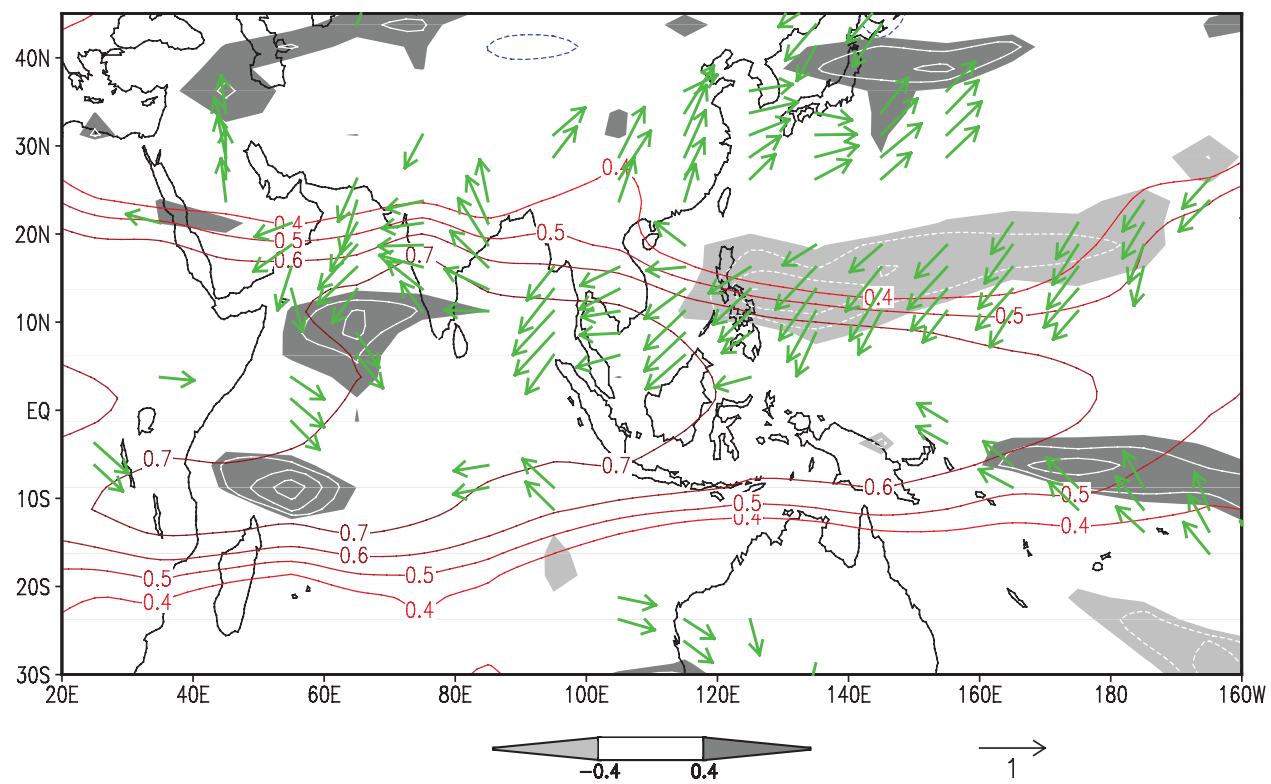

FIG. 6. JJA(1) correlation with the NDJ(0) Niño-3.4 SST index: tropospheric (850-250 hPa) temperature (contours), precipitation (white contours at intervals of 0.1 ; dark shade $>0.4$; light $<-0.4$ ), and surface wind velocity (vectors).

over the NW Pacific excite an equatorial Kelvin wave of an opposite sign, weakening the warm Kelvin wave wedge emanating from the TIO. Indeed, the warm Kelvin wave wedge is much shorter in zonal extension than the off-equatorial Rossby waves to the west (Fig. 4c), opposite to the Matsuno-Gill model prediction. ${ }^{1}$ In the warm Kelvin wave wedge near the equator, precipitation anomalies are not very coherent as the deep subsidence of the wave in the free troposphere opposes the surface convergence in creating precipitation changes. Section 4 tests this hypothesis further with an atmospheric GCM.

Modeling studies suggest a TIO contribution to the NW Pacific anticyclone anomaly during MAM(1) (Su et al. 2001; Watanabe and Jin 2003; Annamalai et al. 2005). We note that from the NIO to NW Pacific during MAM(1), northeasterly wind anomalies and the negative precipitation band are located on the northern edge of the warm Kelvin wave wedge (Fig. 3c). This collocation of surface anomalies with the Kelvin wave's northern flank is consistent with our Kelvin WIED mechanism.

\section{d. Northwest Pacific precipitation}

The NW Pacific warm pool reaches far north during summer, with the $27^{\circ} \mathrm{C}$ SST contour expanding north

\footnotetext{
${ }^{1}$ Factors such as the mean flow and its shear as well as heating latitude also influence the apparent zonal extent of these waves.
}

of $30^{\circ} \mathrm{N}$ (Fig. 7). In addition to the basin-scale intertropical convergence zone (ITCZ) anchored by an offequatorial warm SST band, a subtropical rainband develops during late summer and early fall (JulySeptember) in the NW Pacific, riding on the expanding warm pool. This subtropical rainband appears as a local meridional maximum in precipitation $\left(15^{\circ}-25^{\circ} \mathrm{N}\right)$, and it is a key element of the NW Pacific monsoon (Murakami and Matsumoto 1994; Wang and LinHo 2002). The lateJuly onset of this subtropical NW Pacific convection weakens and displaces the mei-yu-baiu rainband northward that covers east China and Japan during June to mid-July (Ueda et al. 1995, 2009).

Interestingly, summer precipitation variance is much stronger in the subtropical rainband than in the ITCZ over the NW Pacific despite the mean precipitation being much larger in the latter (Fig. 7). Figure 8a shows the time-latitude section of local correlation between monthly SST and precipitation over the western Pacific. In the subtropical NW Pacific, the subtropical rainfall variance intensifies during July-September but is not correlated with the local SST. Our analysis of ENSO correlation indicates that much of the subtropical NW Pacific rainfall variability is instead remotely forced, by the TIO warming in particular. This TIO capacitor effect is pronounced during JJA(1), possibly corresponding to interannual variability in the onset and early development period of subtropical NW Pacific convection. The cause of high variance from August onward needs further investigation. 

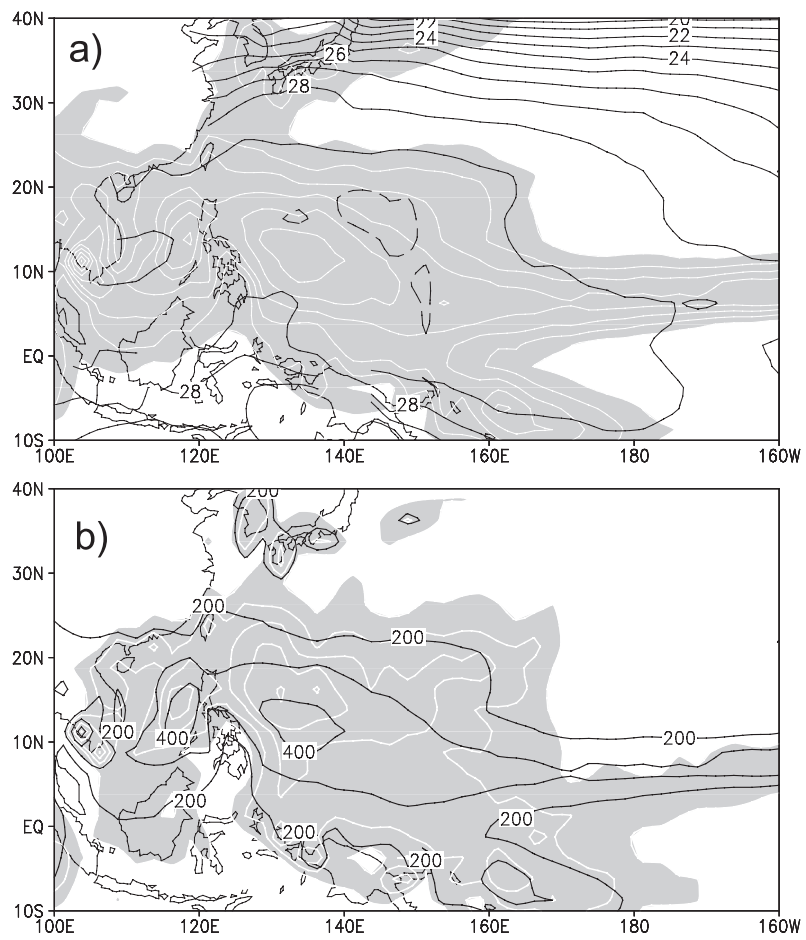

FIG. 7. (a) July-September climatology of SST (black contours with $29.5^{\circ} \mathrm{C}$ dashed) and precipitation (shade $>150 \mathrm{~mm} \mathrm{month}^{-1}$; white contours at $50 \mathrm{~mm}$ month $^{-1}$ intervals). (b) Standard deviation of precipitation for July-September (shade $>75 \mathrm{~mm}$ month $^{-1}$; white contours at $25 \mathrm{~mm}$ month $^{-1}$ intervals), along with the precipitation climatology (black contours).

The anticyclone anomaly over the subtropical NW Pacific begins to develop during the El Niño winter. Figure 9 shows the ENSO correlations of precipitation (shade), SST (color contours), and surface wind velocity in the NW Pacific. In Fig. 9, the onset of the El Niñoinduced anticyclone in December(0) is manifested as the sudden appearance of the anomalous northerlies and SST cooling in $0^{\circ}-10^{\circ} \mathrm{N}$. Wang et al. (2000) suggest that the rapid onset of the anticyclone and SST cooling is due to their mutual interaction as follows. The SST cooling north of the equator reduces precipitation, exciting a westward-propagating Rossby wave. The resulting northerly wind anomalies intensify the mean northeast trades and amplify the initial SST cooling via evaporation and wind stirring. Hereafter we call this the WES-V feedback to emphasize the importance of meridional wind perturbations, where the traditional WES feedback considers the zonal wind effect on evaporation (Xie and Philander 1994). Mean northerly winds $(V)$ are a necessary condition for this WES-V feedback, which is indeed met during December-April (Fig. 8b). (One may use $V=2 \mathrm{~m} \mathrm{~s}^{-1}$ as a threshold for the WES-V feedback to operate given that weather-related variance is high in the ITCZ.) The mean northerlies weaken from February on, and the WES-V mechanism is unlikely to be important from April into the summer, as corroborated by the rapid transition of the local SST-precipitation correlation from positive to negative in $0^{\circ}-10^{\circ} \mathrm{N}$ during April-July (Fig. 8a). Here we have used the SST-precipitation correlation as a test for the ocean-to-atmospheric feedback.

Figure 9 shows that ENSO correlations also display a rapid transition from May(1) to July(1). The center of negative rainfall correlation is confined to $0^{\circ}-10^{\circ} \mathrm{N}$ up to May(1), and jumps to $10^{\circ}-20^{\circ} \mathrm{N}$ in June(1). The northward shift is also seen in the center of the anticyclonic vorticity (as measured by the meridional shear). The northward shift in the anticyclonic center suggests that different mechanisms are at work before May(1) and during JJA(1), consistent with our inference that Pacific and TIO SST anomalies are important for the respective periods. The northward shift of precipitation correlation is also consistent with the evolution of precipitation variance, whose maximum shifts from the ITCZ during winter and spring to the subtropical rainband during summer. The El Niño-induced negative SST anomalies in the ITCZ decay rapidly from April(1). At $145^{\circ} \mathrm{E}$, the negative JJA(1) precipitation anomalies at $15^{\circ} \mathrm{N}$ are not associated with significant SST correlation (Fig. 9), indicating the importance of remote forcing for the maintenance of the subtropical anticyclone during JJA(1).

\section{e. Further teleconnections}

Atmospheric anomalies in the subtropical NW Pacific during JJA(1) excite additional teleconnections in both the ocean and atmosphere. In the ocean, the anticyclonic wind curl anomalies force downwelling Rossby waves that propagate westward (results not shown from an ocean reanalysis), leading to a rise in sea level at Ishigaki Island that peaks in the following December (Fig. 2d), almost a year after the mature phase of El Niño. In the atmosphere, the southwesterly anomalies on the western flank of this anomalous anticyclone transport moisture from the SCS, increasing summer rainfall over the mid-/lower reaches of the Yangtze River of China. Suppressed convection over the subtropical NW Pacific, through upper-tropospheric convergence, excites the Pacific-Japan (PJ) teleconnection (Nitta 1987), with a low pressure centered east of Japan (Fig. 6). Developing under the vertically sheared climatological meridional flow, the PJ vorticity anomalies exhibit an apparent poleward phase tilt with height (Kosaka and Nakamura 2006). The surface low around Japan is associated with an anomalous increase in local precipitation near Japan as observed at Hachijo Island (Fig. 2a). 

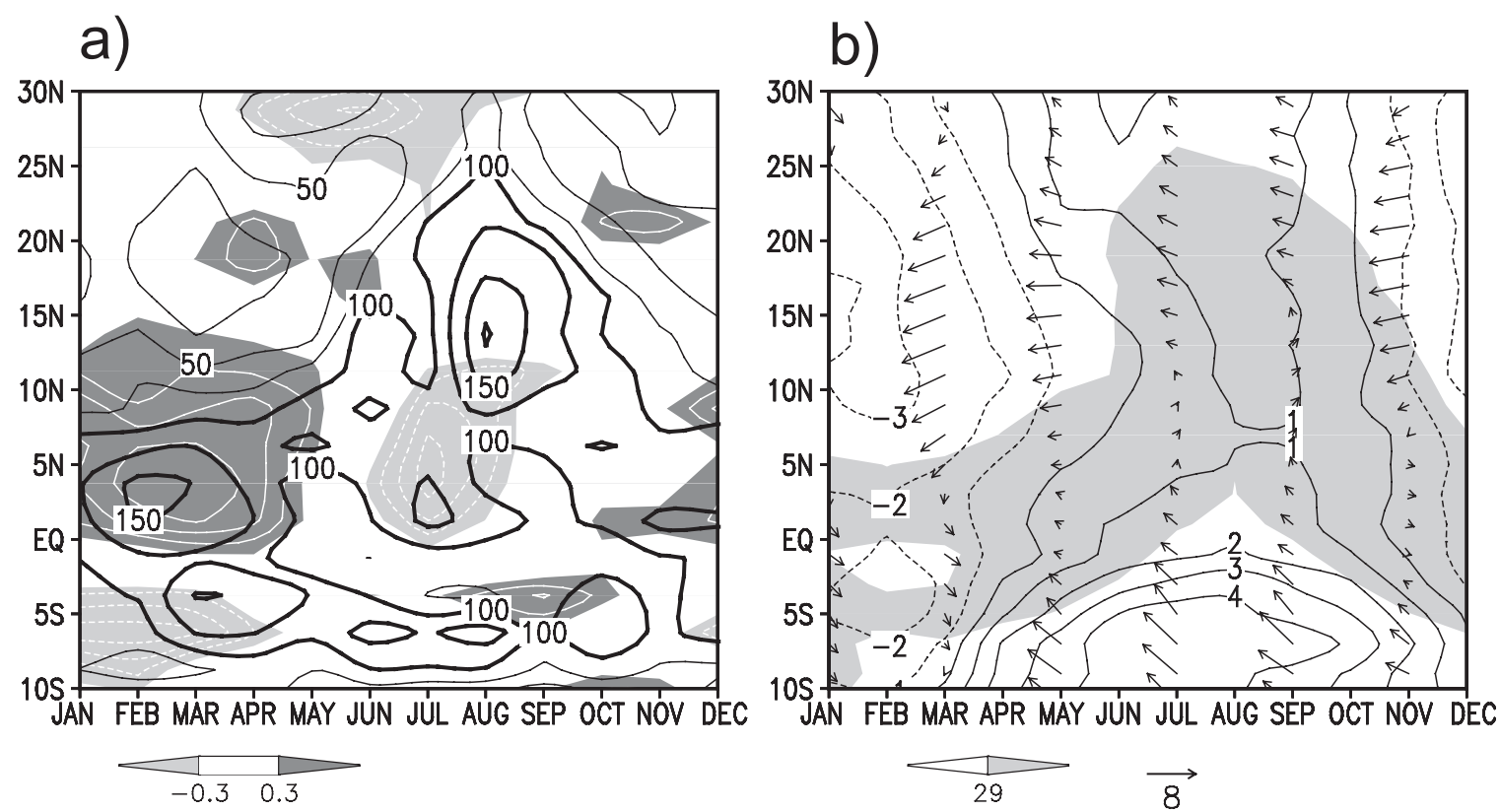

FIG. 8. (a) Monthly precipitation standard deviation (black contours, $\mathrm{mm} \mathrm{month}^{-1}$ ) and SST-precipitation correlation (dark shade $>0.3$; light $<-0.3$; white contours at 0.1 intervals) at $145^{\circ} \mathrm{E}$ as a function of time and latitude. (b) ICOADS climatology of surface wind velocity (vectors, $\mathrm{m} \mathrm{s}^{-1}$ ), its meridional component (contours), and regions with SST $>29^{\circ} \mathrm{C}$ (shade) as a function of time and latitude over the western Pacific $\left(145^{\circ} \mathrm{E}\right)$.

\section{Model results}

This section uses atmospheric GCM experiments to test the hypothesis that the TIO warming affects NW Pacific climate during summer. In the GCM, the imposed TIO warming ${ }^{2}$ causes precipitation to increase over much of the basin (Fig. 10a). Over the equatorial Indian Ocean, precipitation somehow decreases despite the SST increase. Precipitation decreases and a surface anticyclone forms over the subtropical NW Pacific, with a cyclonic circulation to the northeast of Japan. In $0^{\circ}-20^{\circ} \mathrm{N}$ from the NIO to western Pacific, the southwest monsoonal winds weaken, helping sustain the SST warming there in observations (Xie et al. 2003; Du et al. 2009). The model response is qualitatively consistent with observations (Figs. 4 and A1), but the NW Pacific anomalies are too weak while TIO precipitation anomalies too large. This result is consistent with a multimodel study of Li et al. (2008).

\footnotetext{
${ }^{2}$ Care needs to be taken in designing SST-forced, atmospheric GCM experiments because SST changes may be a response to a remote forcing as happens over the TIO during the developing and mature phases of ENSO (Kumar and Hoerling 1998; Wu et al. 2006; Deser and Phillips 2006; Copsey et al. 2006). Our prescription of TIO SST as forcing here is justified by the facts that it is the most robust SST anomalies of the global ocean during JJA(1) and that tropospheric temperature anomalies are consistent with a MatsunoGill pattern forced by a heat source over the TIO (Fig. 4).
}

TIO-induced tropospheric warming forms a spatial pattern reminiscent of the Matsuno-Gill pattern, with the Kelvin wave response extending eastward and covering the entire equatorial Pacific (Fig. 10b). Compared with JJA(1) observations (Fig. 4), the eastward extension of the baroclinic Kelvin wave response is too large, resulting in unrealistic, strong surface easterly anomalies over the equatorial Pacific. This too-strong Kelvin wave response is related to too weak a precipitation reduction over the NW Pacific, which would otherwise excite a baroclinic Kelvin wave of the opposite sign and leaves little net anomalies in the equatorial Pacific. Thus, TIO warming indeed forces a baroclinic Kelvin wave with low SLP centered on the equator, triggering a precipitation reduction and surface anticyclone to the north. The model result of too weak a NW Pacific response suggests that the feedback between local convection and circulation is important for their anomalies to amplify and reach the observed magnitude. A comparison with the observed JJA climatology indicates that model precipitation is weaker by a factor of 2 over the subtropical NW Pacific, limiting the convection-circulation feedback. The poor simulations of subtropical NW Pacific summer rainfall have been flagged as a major problem for atmospheric GCMs (Kang et al. 2002).

The Japan pole of the PJ pattern is too weak and shifted northward compared to observations. Such deficiencies may be due to too-weak convective anomalies 


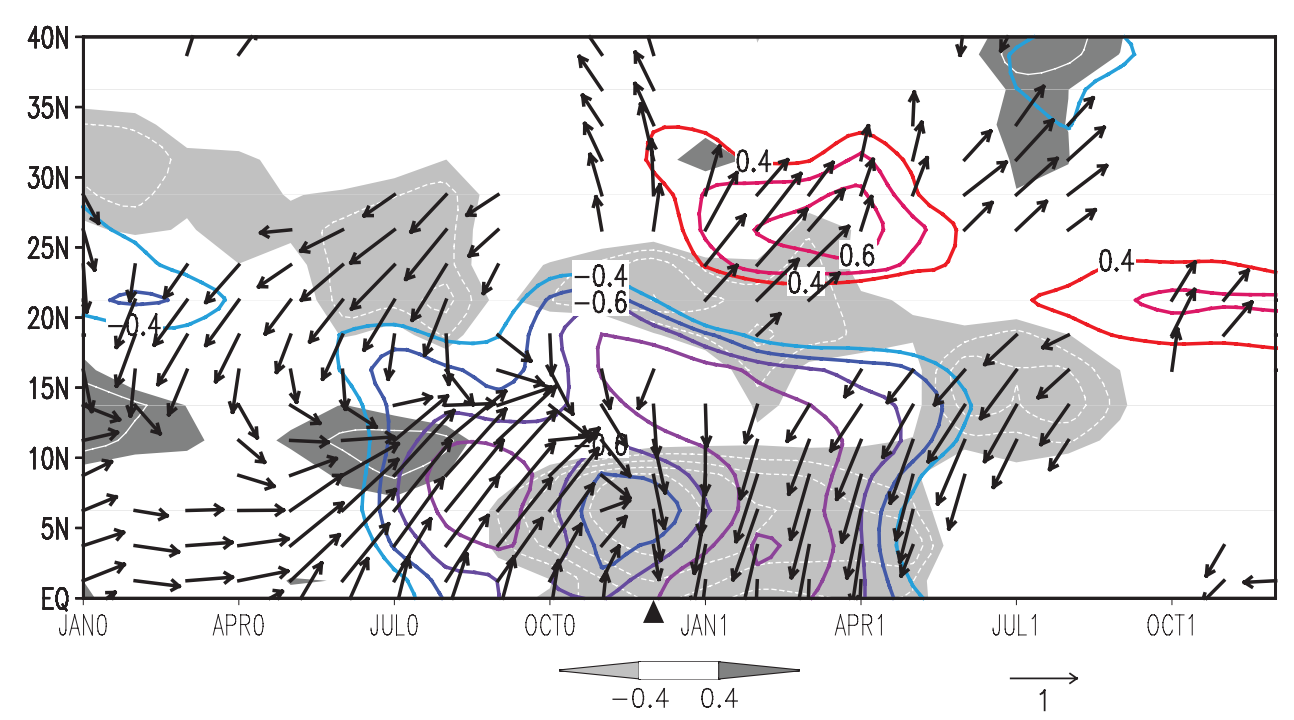

FIG. 9. Time-latitude section of correlation at $145^{\circ} \mathrm{E}$ with the NDJ(0) Niño-3.4 index: SST (color contours), precipitation (dark shade $>0.4$; light shade $<-0.4$; white contours at 0.1 intervals), and surface wind velocity (vectors). The black triangle denotes December(0), the peak phase of ENSO.

in the subtropical NW Pacific and/or errors in simulating mean precipitation and mean flow, from which the PJ mode draws energy (Kosaka and Nakamura 2006).

\section{a. Linear baroclinic model}

To illustrate the importance of the convectioncirculation feedback, we turn to a primitive-equation model linearized around the observed JJA mean state a) $\mathrm{TIO}$

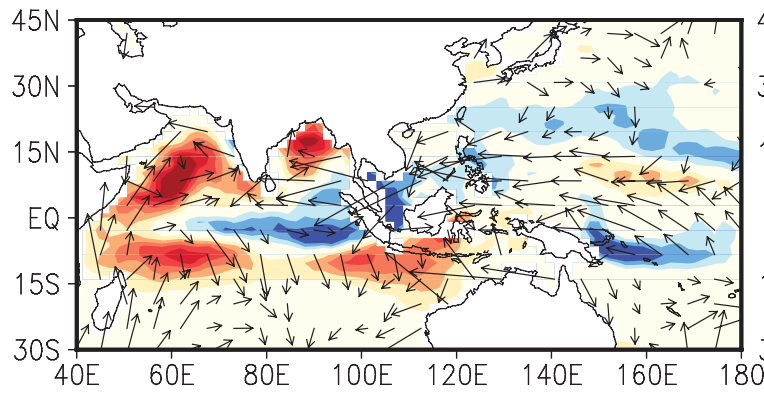

b) $\mathrm{T} 250-850$ (TIO)

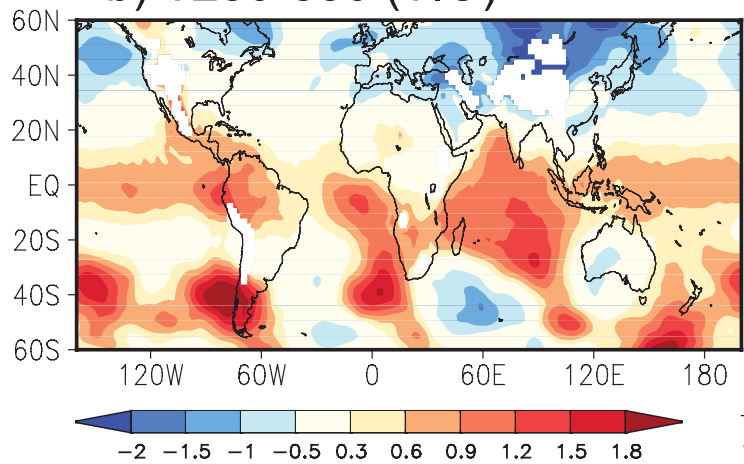

c) TIO-SIO

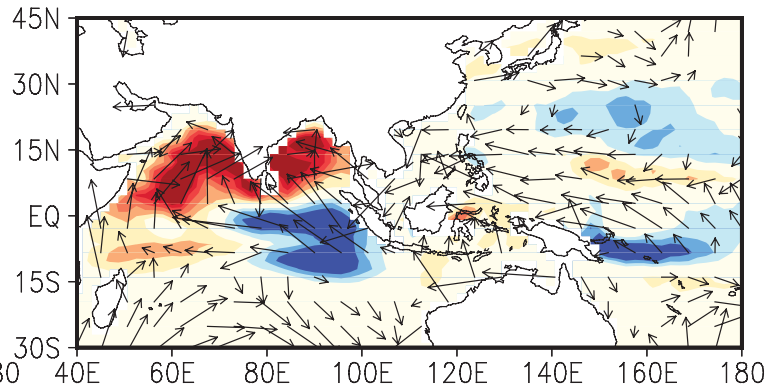

d) $\mathrm{SIO}$

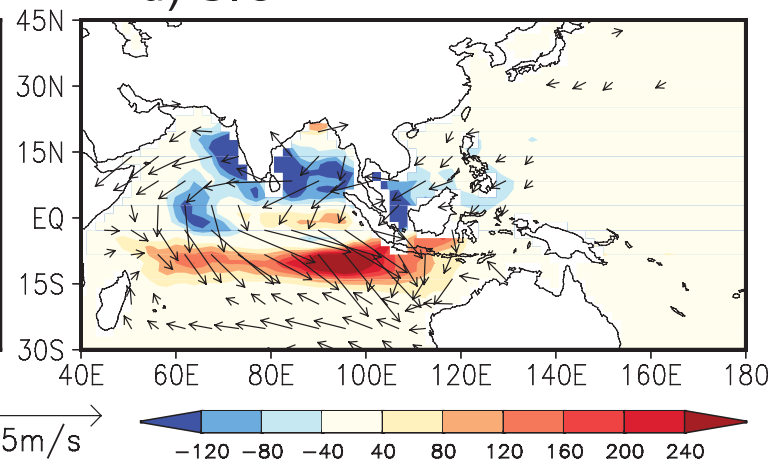

FIG. 10. Anomalies of precipitation (color, $\mathrm{mm} \mathrm{month}^{-1}$; right color bar) and surface wind velocity ( $\mathrm{m} \mathrm{s}^{-1}$; wind speed smaller than $0.5 \mathrm{~m} \mathrm{~s}^{-1}$ has been masked out) in (a) the TIO and (d) SIO atmospheric GCM runs, and (c) TIO-SIO difference. (b) Anomalies of tropospheric temperature $\left({ }^{\circ} \mathrm{C}\right.$; left color bar) in the $250-850-\mathrm{hPa}$ layer in the TIO run. 


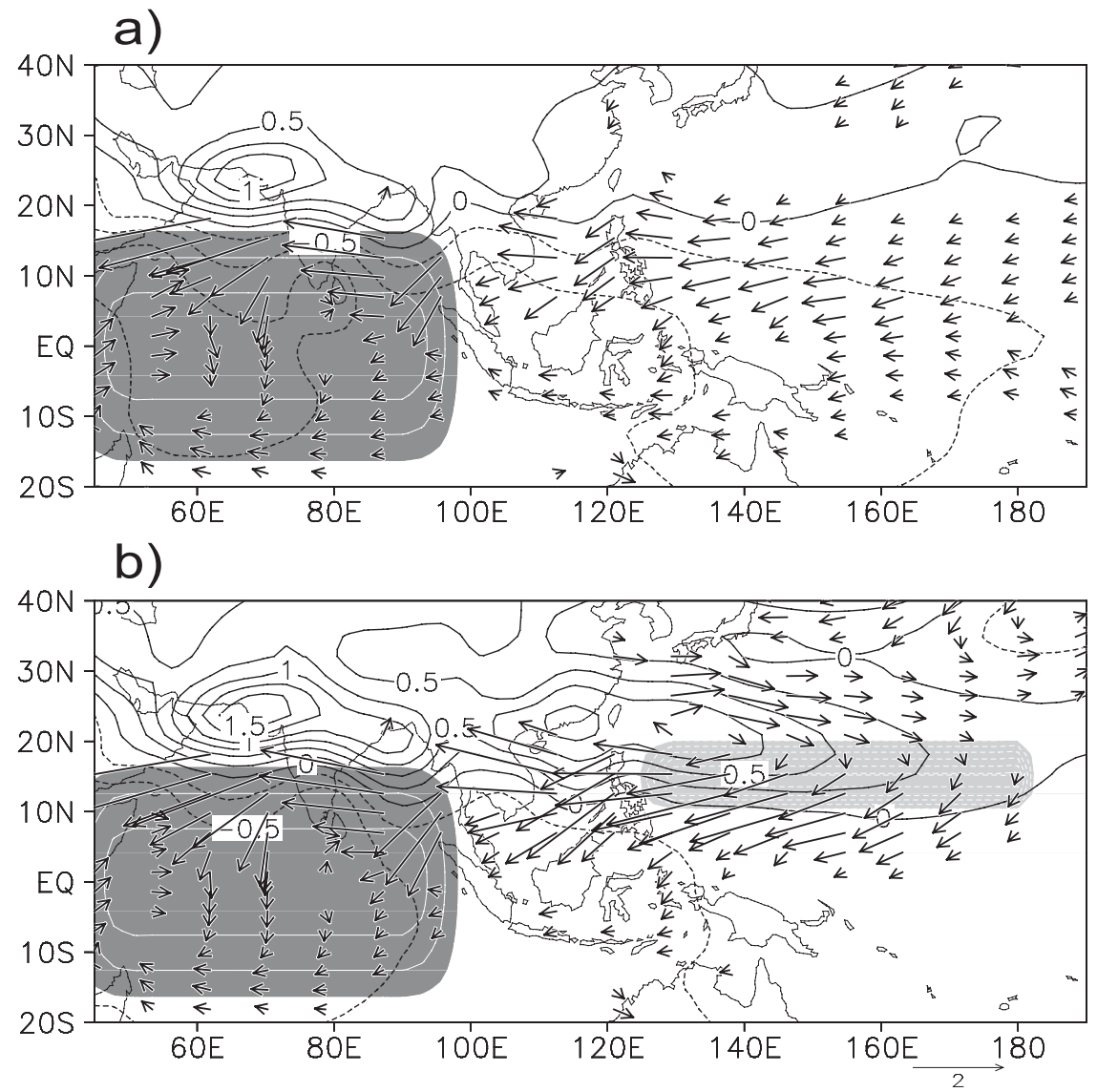

FIG. 11. The linear atmospheric model response to the TIO heating (a) with and (b) without interactive heating over the subtropical NW Pacific: sea level pressure (black contours, hPa), wind velocity $\left(\mathrm{m} \mathrm{s}^{-1}\right)$ at $1000 \mathrm{hPa}$, and diabatic heating rate at $500 \mathrm{hPa}$ (dark shade $>0.25$; light $<-0.25 \mathrm{~K} \mathrm{day}^{-1}$; white contours at $0.25 \mathrm{~K} \mathrm{day}^{-1}$ intervals).

as represented by the NCEP-NCAR reanalysis. The detailed description of the linear baroclinic model (LBM) may be found in Watanabe and Kimoto (2000). We use a version with $\mathrm{T} 42$ resolution in the horizontal and 20 sigma levels in the vertical. The model is forced by prescribed diabatic heating. In the vertical, the heating is confined between 900 and $100 \mathrm{hPa}$, with a peak at 500 $\mathrm{hPa}$ to mimic condensational heat release in deep convection. The heating $(Q)$ is confined in the horizontal, following a half-cosine function in latitude $(y)$,

$Q=Q_{0} \cos \pi\left[\left(y-y_{s}\right) /\left(y_{n}-y_{s}\right)-1 / 2\right]$, for $y_{s}<y<y_{n}$.

Within a longitudinal band $x_{w}<x<x_{e}$, it is zonally uniform except in a $5^{\circ}$ zone on east and west sides where it ramps off to zero.

Figure 11a shows the LBM surface response near the steady state to a broad heating over the TIO: $x_{w}=$ $40^{\circ} \mathrm{E}, x_{e}=100^{\circ} \mathrm{E} ; y_{s}=20^{\circ} \mathrm{S}, y_{n}=20^{\circ} \mathrm{N}$. The maximum heating rate is set at $1 \mathrm{~K}$ day $^{-1}$. Because of the strong monsoon circulation in the JJA mean state, the lowlevel circulation anomalies are rather asymmetric, with a stronger response north than south of the equator. Equatorial symmetry strengthens at upper levels and near the international date line near the surface. The Kelvin wave response is visible in the sea level pressure field. On the northern flank of the Kelvin wave, surface friction turns the winds northeasterly, causing surface divergence there.

To test whether this Kelvin wave-induced divergence would lead to a strong anticyclone with the help of convection-circulation feedback, we conduct the following experiment with interactive heating over the NW Pacific. For simplicity, the horizontal and vertical structure of the interactive heating follows Eq. (1), with $x_{w}=120^{\circ} \mathrm{E}, x_{e}=180^{\circ} ; y_{s}=10^{\circ} \mathrm{N}, y_{n}=20^{\circ} \mathrm{N}$, a NW Pacific region chosen based on observations (Fig. 4). The magnitude of convective heating is parameterized as a linear function of surface convergence $Q_{0}=-\alpha \nabla \bullet u_{s}$, 
where $\mathbf{u}_{\mathrm{s}}$ is the perturbation surface wind velocity averaged in the same NW Pacific region, and the coefficient $\alpha$ controls the strength of the convection-circulation feedback. Although crude, the empirically based parameterization is intended to illustrate the effect of this feedback on the development of NW Pacific anomalies in response to the TIO heating. The LBM is forced by the same broad TIO heating as before, but with an additional, interactive heat source over the NW Pacific. Convective feedback coefficient $\alpha$ is chosen so that the maximum heating rate is $1.8 \mathrm{~K} \mathrm{day}^{-1}$ in the steady state. The results are qualitatively insensitive to the choice of $\alpha$.

Figure $11 \mathrm{~b}$ shows the LBM response on day 30 when it is in a nearly steady state. The model response is now dominated by a strong anticyclone from the SCS to NW Pacific, where the convection-circulation feedback amplifies the Kelvin wave-induced Ekman divergence and maintains a strong diabatic cooling. The model response resembles observed anomalies during JJA(1) from the north Indian Ocean to the NW Pacific (Figs. 4 and A1), including anomalous easterlies in $10^{\circ}-20^{\circ} \mathrm{N}$ from the Arabian Sea to the international date line. The importance of reduced convection over the NW Pacific for the anticyclonic circulation is consistent with Terao and Kubota's (2005) linear model study using prescribed heating. The LBM with interactive NW Pacific heating even simulates a weak cyclonic circulation east of Japan, consistent with observations and with Kosaka and Nakamura's (2006) suggestion that the PJ pattern is a dynamical mode of the atmosphere shaped by the summer mean flow. The general agreement between the LBM experiment and observations supports our hypothesis that the Kelvin wave forced by the TIO warming triggers the suppression of convection and the development of a surface anticyclone over the NW Pacific.

\section{b. North Indian Ocean effect}

An additional GCM experiment has been carried out to narrow down the TIO subdomain that is most important for the formation of the NW Pacific anticyclone. In the SIO run where the SST increase is limited to the tropical South Indian Ocean (SIO), precipitation increases south and decreases north of the equator, with a C-shaped, antisymmetric wind pattern (Fig. 10d), similar to observations over the western TIO (Fig. 6). The positive and negative anomalies of this precipitation dipole in the meridional direction are nearly equal in magnitude, rendering a small basin mean. As a result, anomalies over the Pacific are negligible. Figure 10c shows the TIO-SIO difference, which may be taken as the response to an NIO warming. The rainfall increase over the NIO is much larger than the reduction south of the equator. The net increase in the basin-mean precipitation forces a
Kelvin wave response with low pressure and easterly wind anomalies over the equatorial Pacific, triggering a reduction in precipitation and the formation of a surface anticyclone over the subtropical NW Pacific. These model results indicate that SST anomalies over the NIO are more important for NW Pacific summer anomalies than those over the SIO. The preference for the NIO is likely due to higher mean SST, and hence stronger SST forcing of the atmosphere than over the SIO.

Figure 12 shows the observed SST correlation with a summer NW Pacific anticyclone index defined as the $\left(27.5^{\circ}-32.5^{\circ} \mathrm{N}\right)$ minus $\left(10^{\circ}-15^{\circ} \mathrm{N}\right)$ difference in surface zonal wind averaged in $130^{\circ}-160^{\circ} \mathrm{E}$. The correlation is low with local SST but strong over the NIO and SCS, corroborating the GCM results. SST correlation is also high over the equatorial southeast Indian Ocean, where negative IOD events sometimes develop during JJA(1), as in 1998. GCM results show that during summer of 1998, the east equatorial Indian Ocean warming is important in reducing precipitation anomalies in East Asian and the NW Pacific (Shen et al. 2001). There is a tendency for NW Pacific precipitation to correlate negatively with that over the TIO, the middle reach of the Yangtze River, and near Japan, broadly consistent with the GCM.

\section{Summary and discussion}

We have investigated ENSO-induced anomalies during the summer [JJA(1)] following its peak phase using observations and atmospheric models. The anticyclone centered in the subtropical NW Pacific emerges as the dominant anomaly pattern in the lower troposphere from our correlation and EOF analyses. This anomalous anticyclonic circulation explains many regional JJA(1) climate anomalies related to ENSO in Fig. 2. The weakened southwest monsoon causes the SCS to warm up; precipitation decreases at Guam and SLP increases in the anticyclone; the negative wind curls force downwelling ocean Rossby waves detected as a sea level rise at Ishigaki Island a few months later; and the PJ teleconnection from the subtropics intensifies baiu rainfall over Japan as observed at Hachijo Island.

Such summer atmospheric anomalies must be anchored by SST anomalies somewhere even though eastern Pacific SST anomalies have dissipated by JJA(1). The SST increase over the TIO and SCS is the most robust ocean anomaly pattern during JJA(1), making it a likely cause of persistent atmospheric anomalies (block arrow in Fig. 13). The tropospheric temperature anomaly pattern resembles the MatsunoGill response to a localized heat source over the TIO, offering additional support for the capacitor mechanism in which the El Niño-induced TIO warming 


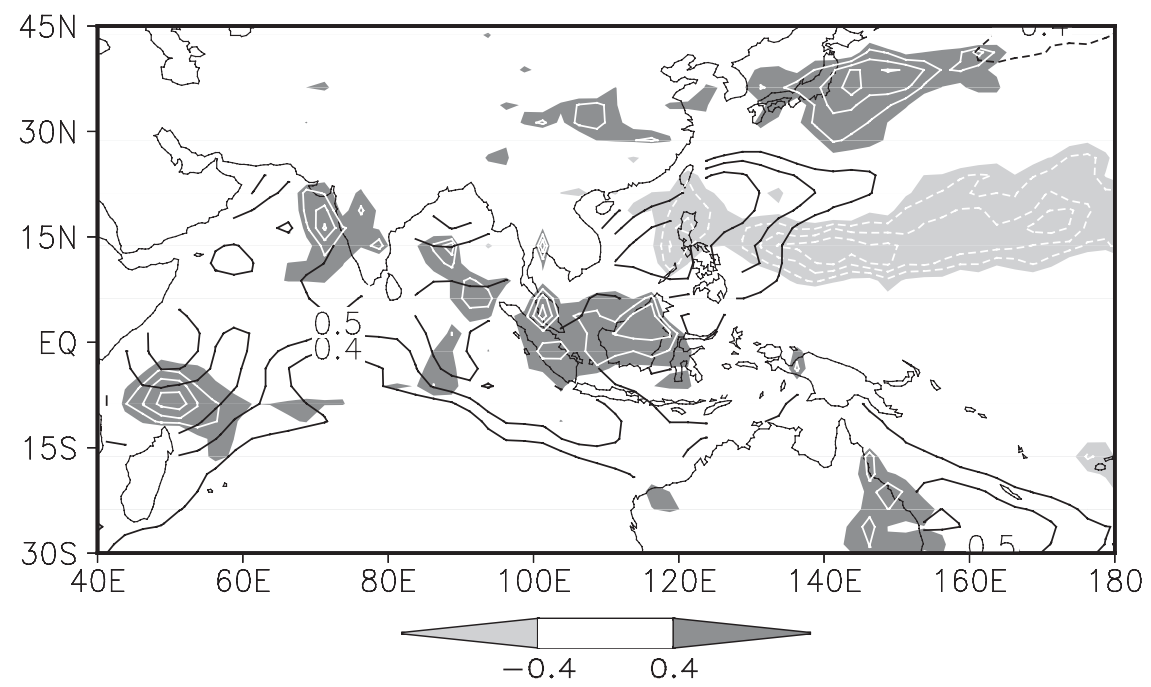

FIG. 12. Precipitation (gray shade and white contours) and SST (black contours) correlation during JJA with a NW Pacific anticyclone index, defined as $\left(27.5^{\circ}-32.5^{\circ} \mathrm{N}\right)$ minus $\left(10^{\circ}-15^{\circ} \mathrm{N}\right)$ zonal wind difference averaged in $120^{\circ}-150^{\circ} \mathrm{E}$. Only correlation above \pm 0.4 is shown, and contour intervals are 0.1 .

persists through the summer and sustains atmospheric anomalies after El Niño itself is gone. Observed precipitation anomalies are weak over the TIO, suggesting the moist-adiabatic adjustment as the mechanism for the SST forcing of tropospheric temperature.

Atmospheric GCM experiments show that the long persistence of positive SST anomalies outside the tropical Pacific maintains the delayed tropospheric warming during and after the decay of El Niño (Kumar and Hoerling 2003; Lau et al. 2005). Our results suggest that this tropospheric warming triggers the suppression of NW Pacific convection. To our knowledge, our study is the first that relates these two robust atmospheric anomaly patterns that outlast El Niño. The JJA(1) tropospheric warming displays a Kelvin wave wedge extending into the western Pacific, acting to lower SLP near the equator and induce northeasterly winds and divergence north of the equator. The Ekman divergence initiates the suppression of deep convection over the NW Pacific (Fig. 6). The linear atmo- spheric model results support the Kelvin WIED mechanism and illustrate the importance of circulationconvection feedback for amplifying the surface high over the NW Pacific: surface divergence in the high pressure suppresses convection while the reduced latent heating intensifies the high and anticyclonic circulation.

We have conducted an atmospheric GCM experiment by increasing SST over the TIO. The model reproduces the baroclinic Kelvin wave over the equatorial Pacific and the anticyclone anomaly in the NW Pacific, in support of the above Kelvin wave-induced Ekman divergence mechanism. The NW Pacific anticyclone is too weak compared to observations because the model underestimates the summer precipitation climatology in the subtropical rainband, and hence the local circulationconvection feedback. An additional experiment with the SST warming confined to the south of the equator indicates that the NIO SST warming is the most important forcing of the Pacific response both on and north of the equator. This model result is consistent

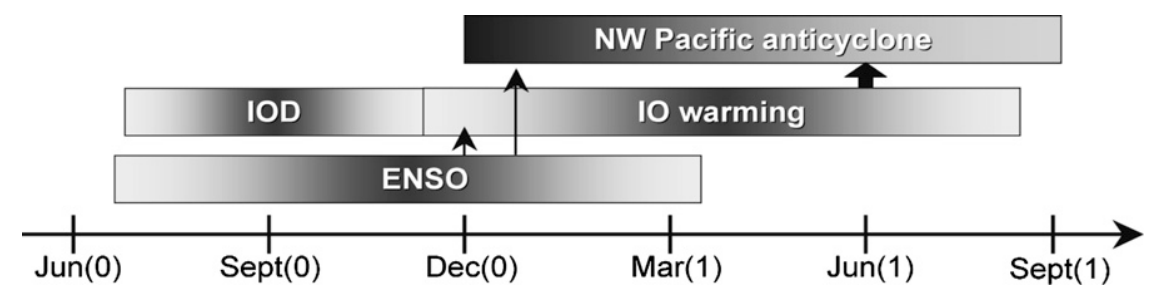

FIG. 13. Seasonality of major modes of Indo-western Pacific climate variability. Vertical arrows indicate causality, and the block arrow emphasizes the TIO capacitor effect, the major finding of the present study. 

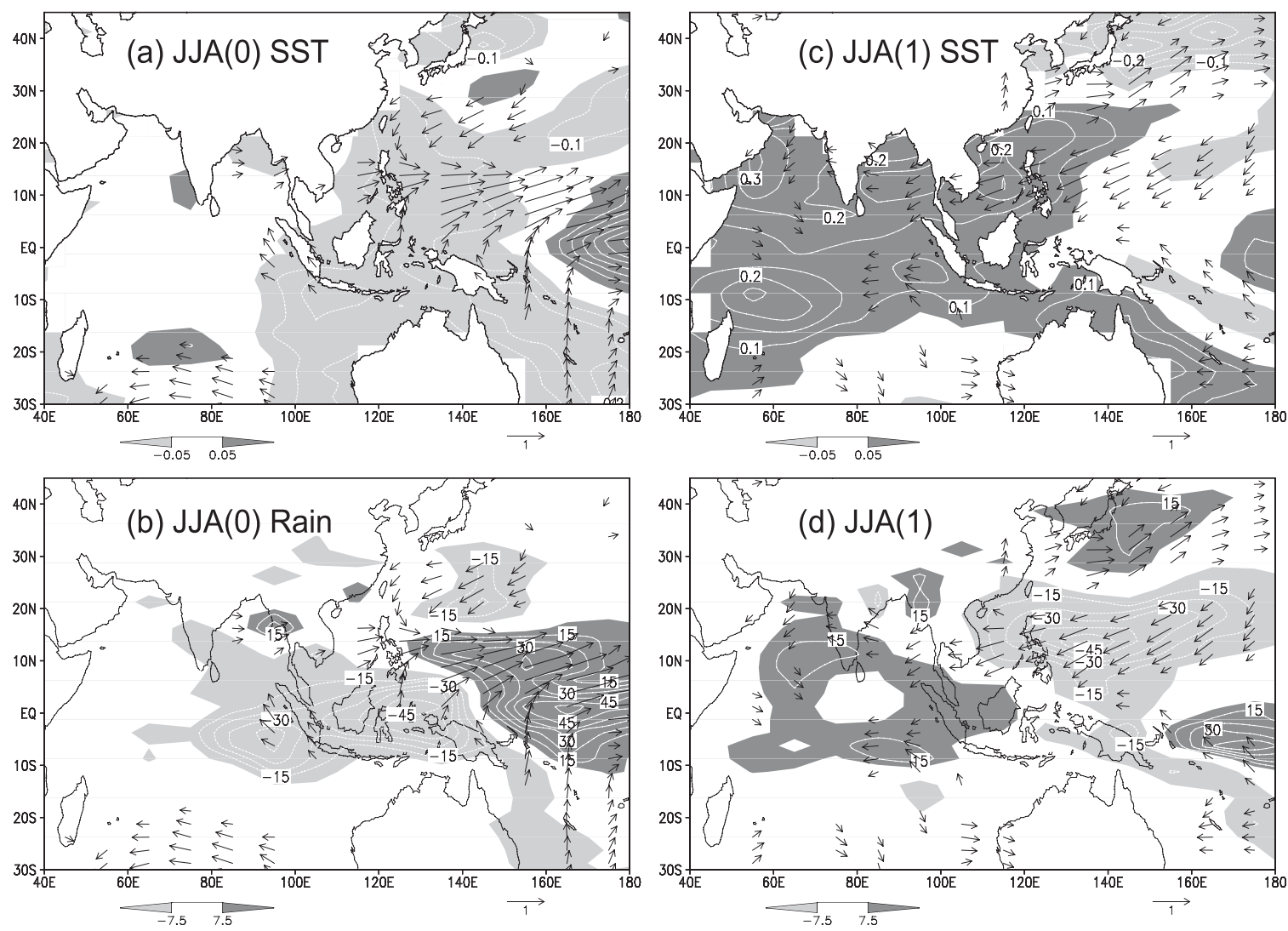

FIG. A1. Regression upon the NDJ(0) Niño-3.4 index for (left) JJA(0) and (right) JJA(1): (top) SST ( $\left.{ }^{\circ} \mathrm{C}\right)$ and (bottom) precipitation $\left(\mathrm{mm}\right.$ month $\left.^{-1}\right)$.

with the observational analysis that NW Pacific anticyclone is most highly correlated with NIO SST.

The NW Pacific anticyclone anomaly begins to develop at the peak of El Niño and persists through the following summer (Harrison and Larkin 1996; Wang et al. 2003). The center of this anticyclone, as well as the center of negative precipitation anomalies, displays a northward shift from $5^{\circ}-10^{\circ} \mathrm{N}$ during winter to $15^{\circ} \mathrm{N}$ during summer (Fig. 9). This meridional shift reflects a change in mechanism for maintaining the anticyclone. During winter, the precipitation decrease is collocated with negative SST anomalies, with the latter possibly being induced by the intensified northeasterly trades through the WES-V mechanism (Wang et al. 2000) with contributions from the TIO warming via the Kelvin WIED mechanism. During JJA(1), the precipitation decrease is most highly correlated with NIO SST, reflecting the remote influence from there, likely via the baroclinic Kelvin wave. Local JJA(1) SST anomalies are rather complicated, varying from positive in the western to marginally negative in the central and eastern parts of the NW Pacific anticyclone (Fig. 4).

The schematic in Fig. 13 summarizes the results. El Niño develops during the summer of year 0 , peaks in winter, and decays in the spring of year 1 . It induces the basin-wide warming over the TIO that persists through JJA(1). During the summer following El Niño, the TIO warming is the main culprit for the anomalous anticyclone and suppressed rainfall over the subtropical NW Pacific.

The following important question still remains: how is the TIO warming maintained through JJA(1)? A companion paper (Du et al. 2009) suggests that oceanatmosphere interaction within the TIO is important.

TABLE A1. Statistics of summer (JJA) EOF modes over the Indo-western Pacific: explained variance (row 2), and season relative to the peak of El Niño (row 3 ) inferred from correlation (r) with the NDJ(0) ENSO index (row 4). For comparison, row 5 lists the simultaneous correlation with the JJA ENSO index. The PC pairs of (SST-2, Rain-1) and (SST-1, Rain-2) are correlated at 0.78 and 0.74 , respectively.

\begin{tabular}{lcccc}
\hline \multicolumn{1}{c}{ EOF } & SST-2 & Rain-1 & SST-1 & Rain-2 \\
\hline Variance (\%) & 16 & 21 & 29 & 17 \\
Season inferred & JJA(0) & JJA(0) & JJA(1) & JJA(1) \\
r-Niño NDJ(0) & 0.71 & 0.76 & 0.69 & 0.75 \\
r-Niño JJA & 0.66 & 0.72 & 0.33 & 0.05 \\
\hline
\end{tabular}


Specifically, the downwelling ocean Rossby wave anchors the warming, not only over the SWIO thermocline dome but also over the NIO by inducing northeasterly wind anomalies, which relax the southwest monsoon during early summer and reduce latent heat flux from the ocean.

Acknowledgments. We wish to thank R.-H. Huang, Q. Liu, W. Chen, J. Yang, and H. Annamalai for helpful discussion, M. Watanabe for making the LBM available, G. Wu and T. Terao for pointing us to earlier modeling work on TIO effects, and H. Nakamura and an anonymous reviewer for their useful comments. This work is supported by the U.S. National Science Foundation, Japan Agency for Marine-Earth Science and Technology, Natural Science Foundation of China (NSFC), and Chinese Academy of Sciences (CAS). IPRC/SOEST Publication 541/7584.

\section{APPENDIX}

\section{JJA(0) and JJA(1) Comparison}

A typical El Niño event affects the Indo-western Pacific climate during summers of both its developing and decay years. Figure A1 compares ENSO-induced anomalies between $\mathrm{JJA}(0)$ and $\mathrm{JJA}(1)$ based on a regression analysis referenced to the NDJ(0) ENSO index. During JJA(0), El Niño warming already takes shape over the equatorial Pacific, increasing rainfall and inducing westerly wind anomalies there to sustain the Bjerknes feedback. South of the equator from the Maritime Continent to the eastern Indian Ocean, SST decreases, suppressing atmospheric convection there. Over the eastern Indian Ocean, the SST cooling is coupled with the southeasterly wind anomalies, and the couplet often develops into an Indian Ocean dipole (IOD) mode, growing on the Bjerknes feedback (Saji et al. 1999; Webster et al. 1999; Schott et al. 2008). In the subtropical NW Pacific $\left(15^{\circ}-20^{\circ} \mathrm{N}\right)$, a surface cyclonic anomaly develops as part of the baroclinic Rossby wave forced by the Pacific warming.

While the centers of action for SST, precipitation, and surface winds are in the tropical Pacific during JJA(0), they shift to the Indo-western Pacific during JJA(1), anchored by the TIO warming (Figs. 4 and A1c,d). Decreased precipitation and the anticyclonic circulation over the subtropical NW Pacific are the most pronounced anomalies of the atmosphere during JJA(1). From the NIO to the NW Pacific, anomalies of precipitation and surface winds tend to have opposite signs during JJA(0) and JJA(1). This biennial tendency of the Indo-western Pacific response to ENSO, previously noted (e.g., Wang et al. 2003; Alexander et al. 2004), is due to the difference in forcing mechanism: the JJA(0) anomalies are largely forced directly by eastern Pacific SST while the JJA(1) anomalies are largely forced by TIO SST.

We have performed EOF analyses separately for precipitation and SST over the Indo-western Pacific Oceans $\left(20^{\circ} \mathrm{S}-40^{\circ} \mathrm{N}, 40^{\circ} \mathrm{E}-180^{\circ}\right)$ for the JJA season. The dominant modes are similar to the regression patterns in Fig. A1 (Table A1). Specifically, the second SST and first precipitation modes resemble the JJA(0) regressions, explaining $16 \%$ and $21 \%$ of the total variance, respectively. Their principal components (PCs) correlate highly with the NDJ(0) ENSO index. The first SST and second precipitation EOF modes resemble the JJA(1) regressions, explaining $29 \%$ and $17 \%$ of the total variance, respectively. Their PCs correlate highly with the ENSO index 6 months before [NDJ(0)], but not simultaneously [JJA(1)], which is indicative of the TIO capacitor effect.

\section{REFERENCES}

Alexander, M. A., I. Bladé, M. Newman, J. R. Lanzante, N.-C. Lau, and J. D. Scott, 2002: The atmospheric bridge: The influence of ENSO teleconnections on air-sea interaction over the global oceans. J. Climate, 15, 2205-2231.

- N.-C. Lau, and J. D. Scott, 2004: Broadening the atmospheric bridge paradigm: ENSO teleconnections to the tropical West Pacific-Indian Oceans over the seasonal cycle and to the North Pacific in summer. Earth Climate: The Ocean-Atmosphere Interaction, Geophys. Monogr., Vol. 147, Amer. Geophys. Union, 85-103.

Annamalai, H., P. Liu, and S.-P. Xie, 2005: Southwest Indian Ocean SST variability: Its local effect and remote influence on Asian monsoons. J. Climate, 18, 4150-4167.

Behera, S. K., P. S. Salvekar, and T. Yamagata, 2000: Simulation of interannual SST variability in the tropical Indian Ocean. J. Climate, 13, 3487-3499.

Chiang, J. C. H., and A. H. Sobel, 2002: Tropical tropospheric temperature variations caused by ENSO and their influence on the remote tropical climate. J. Climate, 15, 2616-2631.

_ and B. R. Lintner, 2005: Mechanisms of remote tropical surface warming during El Niño. J. Climate, 18, 4130-4149.

Copsey, D., R. Sutton, and J. R. Knight, 2006: Recent trends in sea level pressure in the Indian Ocean region. Geophys. Res. Lett., 33, L19712, doi:10.1029/2006GL027175.

Deser, C., and A. S. Phillips, 2006: Simulation of the 1976/77 climate transition over the North Pacific: Sensitivity to tropical forcing. J. Climate, 19, 6170-6180.

_ - _ , and J. W. Hurrell, 2004: Pacific interdecadal climate variability: Linkages between the tropics and the North Pacific during boreal winter since 1900. J. Climate, 17, 3109-3124.

Du, Y., and S.-P. Xie, 2008: Role of atmospheric adjustments in the tropical Indian Ocean warming during the 20th century in climate models. Geophys. Res. Lett., 35, L08712, doi:10.1029/ 2008GL033631.

, - - G. Huang, and K.-M. Hu, 2009: Role of air-sea interaction in the long persistence of El Niño-induced North Indian Ocean warming. J. Climate, in press. 
Emanuel, K. A., J. D. Neelin, and C. S. Bretherton, 1997: Reply to comments by Bjorn Stevens, David A. Randall, Xin Lin and Michael T. Montgomery on 'On large-scale circulations in convecting atmospheres.' Quart. J. Roy. Meteor. Soc., 123, 1779-1782.

Enfield, D. B., and D. A. Mayer, 1997: Tropical Atlantic SST variability and its relation to El Niño-Southern Oscillation. $J$. Geophys. Res., 102, 929-945.

Fu, C., and X. Teng, 1988: The relationship between ENSO and climate anomaly in China during the summer time. Sci. Atmos. Sin., 12, 133-141.

Gill, A. E., 1980: Some simple solutions for heat-induced tropical circulation. Quart. J. Roy. Meteor. Soc., 106, 447-462.

Harrison, D., and N. K. Larkin, 1996: The COADS sea level pressure signal: A near-global El Niño composite and time series view, 1946-93. J. Climate, 9, 3025-3055.

Huang, B., and J. L. Kinter III, 2002: Interannual variability in the tropical Indian Ocean. J. Geophys. Res., 107, 3199, doi:10.1029/ 2001JC001278.

Huang, R., and Y. Wu, 1989: The influence of ENSO on the summer climate change in China and its mechanism. $A d v$. Atmos. Sci., 6, 21-32.

— W. When, B. Yang, and R. Zhang, 2004: Recent advances in studies of the interaction between the East Asian winter and summer monsoons and ENSO cycle. Adv. Atmos. Sci., 21, 407-424.

Kalnay, E., and Coauthors, 1996: The NCEP/NCAR 40-Year Reanalysis Project. Bull. Amer. Meteor. Soc., 77, 437-471.

Kang, I.-S., and Coauthors, 2002: Intercomparison of the climatological variations of Asian summer monsoon precipitation simulated by 10 GCMs. Climate Dyn., 19, 383-395.

Kawamura, R., T. Matsumura, and S. Iizuka, 2001: Role of equatorially asymmetric sea surface temperature anomalies in the Indian Ocean in the Asian summer monsoon and El NiñoSouthern Oscillation coupling. J. Geophys. Res., 106, 4681-4693.

Klein, S. A., B. J. Soden, and N.-C. Lau, 1999: Remote sea surface temperature variations during ENSO: Evidence for a tropical atmospheric bridge. J. Climate, 12, 917-932.

Kosaka, Y., and H. Nakamura, 2006: Structure and dynamics of the summertime Pacific-Japan teleconnection pattern. Quart. J. Roy. Meteor. Soc., 132, 2009-2030.

Kumar, A., and M. P. Hoerling, 1998: Specification of regional sea surface temperatures in atmospheric general circulation model simulations. J. Geophys. Res., 103, 8901-8907.

$\longrightarrow$, and - 2003: The nature and causes for the delayed atmospheric response to El Niño. J. Climate, 16, 1391-1403.

Lau, N.-C., and M. J. Nath, 2003: Atmosphere-ocean variations in the Indo-Pacific sector during ENSO episodes. J. Climate, 16, 3-20.

_- A. Leetmaa, M. J. Nath, and H. L. Wang, 2005: Influences of ENSO-induced Indo-western Pacific SST anomalies on extratropical atmospheric variability during the boreal summer. J. Climate, 18, 2922-2942.

Lengaigne, M., J. P. Boulanger, C. Menkes, and H. Spencer, 2006: Influence of the seasonal cycle on the termination of El Niño events in a coupled general circulation model. J. Climate, 19, $1850-1868$.

Li, S., J. Lu, G. Huang, and K. Hu, 2008: Tropical Indian Ocean basin warming and East Asian summer monsoon: A multiple AGCM study. J. Climate, 21, 6080-6088.

Liu, Q., X. Jiang, S.-P. Xie, and W. T. Liu, 2004: A gap in the IndoPacific warm pool over the South China Sea in boreal winter: Seasonal development and interannual variability. J. Geophys. Res., 109, C07012, doi:10.1029/2003JC002179.
Matsuno, T., 1966: Quasi-geostrophic motions in the equatorial area. J. Meteor. Soc. Japan, 44, 25-43.

Murakami, T., and J. Matsumoto, 1994: Summer monsoon over the Asian continent and western North Pacific. J. Meteor. Soc. Japan, 72, 719-745.

Murtugudde, R., and A. J. Busalacchi, 1999: Interannual variability of the dynamics and thermodynamics, and mixed layer processes in the Indian Ocean. J. Climate, 12, 2300-2326.

Neelin, J. D., and H. Su, 2005: Moist teleconnection mechanisms for the tropical South American and Atlantic sector. J. Climate, 18, 3928-3950.

Nitta, T., 1987: Convective activities in the tropical western Pacific and their impact on the Northern Hemisphere summer circulation. J. Meteor. Soc. Japan, 65, 373-390.

Ohba, M., and H. Ueda, 2006: A role of zonal gradient of SST between the Indian Ocean and the western Pacific in localized convection around the Philippines. SOLA, 2, 176-179.

Rayner, N. A., P. Brohan, D. E. Parker, C. K. Folland, J. J. Kennedy, M. Vanicek, T. Ansell, and S. F. B. Tett, 2006: Improved analyses of changes and uncertainties in sea surface temperature measured in situ since the mid-nineteenth century: The HadSST2 dataset. J. Climate, 19, 446-469.

Roeckner, E., and Coauthors, 2003: Atmospheric general circulation model ECHAM5: Part I. Max-Planck-Institut für Meteorlogie Rep. 349, 140 pp.

Saji, N. H., B. N. Goswami, P. N. Vinayachandran, and T. Yamagata, 1999: A dipole mode in the tropical Indian Ocean. Nature, 401, 360-363.

Schott, F. A., S.-P. Xie, and J. P. McCreary, 2008: Indian Ocean circulation and climate variability. Rev. Geophys., in press.

Shen, X., M. Kimoto, A. Sumi, A. Numaguti, and J. Matsumoto, 2001: Simulation of the 1998 East Asian summer monsoon by the CCSR/NIES AGCM. J. Meteor. Soc. Japan, 79, 741-757.

Sobel, A. H., I. M. Held, and C. S. Bretherton, 2002: The ENSO signal in tropical tropospheric temperature. J. Climate, 15, 2702-2706.

Su, H., and J. D. Neelin, 2003: The scatter in tropical average precipitation anomalies. J. Climate, 16, 3966-3977.

- - _ , and C. Chou, 2001: Tropical teleconnection and local response to SST anomalies during the 1997-98 El Niño. $J$. Geophys. Res., 106, 20 025-20 043.

Terao, T., and T. Kubota, 2005: East-west SST contrast over the tropical oceans and the post E1 Niño western North Pacific summer monsoon. Geophys. Res. Lett., 32, L15706, doi:10.1029/ 2005GL023010.

Tokinaga, H., and Y. Tanimoto, 2004: Seasonal transition of SST anomalies in the tropical Indian Ocean during El Niño and Indian Ocean dipole years. J. Meteor. Soc. Japan, 82, 1007 1018.

Trenberth, K. E., G. W. Branstator, D. Karoly, A. Kumar, N.-C. Lau, and C. Ropelewski, 1998: Progress during TOGA in understanding and modeling global teleconnections associated with tropical sea surface temperatures. J. Geophys. Res., 103, 14 291-14 324.

Ueda, H., T. Yasunari, and R. Kawamura, 1995: Abrupt seasonal change of large-scale convective activity over the western $\mathrm{Pa}$ cific in the northern summer. J. Meteor. Soc. Japan, 73, 795-809.

_ M. Ohba, and S.-P. Xie, 2009: Important factors for the development of the Asian-northwest Pacific summer monsoon. J. Climate, in press.

Vecchi, G. A., and D. E. Harrison, 2006: The termination of the 1997-98 El Niño. Part I: Mechanisms of oceanic change. $J$. Climate, 19, 2633-2646. 
Wang, B., and LinHo, 2002: Rainy season of the Asian-Pacific summer monsoon. J. Climate, 15, 386-398.

— , R. Wu, and X. Fu, 2000: Pacific-East Asia teleconnection: How does ENSO affect East Asian climate? J. Climate, 13, 1517-1536.

, - - and T. Li, 2003: Atmosphere-warm ocean interaction and its impact on Asian-Australian monsoon variability. J. Climate, 16, 1195-1211.

_, Q. Ding, X. Fu, I.-S. Kang, K. Jin, J. Shukla, and F. DoblasReyes, 2005: Fundamental challenge in simulation and prediction of summer monsoon rainfall. Geophys. Res. Lett., 32, L15711, doi:10.1029/2005GL022734.

Wang, C., R. H. Weisberg, and J. I. Virmani, 1999: Western Pacific interannual variability associated with the El Niño-Southern Oscillation. J. Geophys. Res., 104, 5131-5149.

_- W. Wang, D. Wang, and Q. Wang, 2006: Interannual variability of the South China Sea associated with El Niño. $J$. Geophys. Res., 111, C03023, doi:10.1029/2005JC003333.

Watanabe, M., and M. Kimoto, 2000: Atmosphere-ocean thermal coupling in the North Atlantic: A positive feedback. Quart. J. Roy. Meteor. Soc., 126, 3343-3369.

_ , and F. F. Jin, 2003: A moist linear baroclinic model: Coupled dynamical-convective response to El Niño. J. Climate, 16, 1121-1139.

Webster, P. J., A. M. Moore, J. P. Loschnigg, and R. R. Leben, 1999: Coupled oceanic-atmospheric dynamics in the Indian Ocean during 1997-98. Nature, 401, 356-360.

Worley, S. J., S. D. Woodruff, R. W. Reynolds, S. J. Lubker, and N. Lott, 2005: ICOADS release 2.1 data and products. Int. J. Climatol., 25, 823-842.

Wu, G. X., and H. Liu, 1995: Neighborhood response of rainfall to tropical sea surface temperature anomalies. Part I: Numerical experiment. Chinese J. Atmos. Sci., 19, 422-434.

_, F. Sun, J. Wang, and X. Wang, 1995: Neighborhood response of rainfall to tropical sea surface temperature anomalies. Part II: Data analysis. Chinese J. Atmos. Sci., 19, 663-676.
Wu, R., B. P. Kirtman, and K. Pegion, 2006: Local air-sea relationship in observations and model simulations. J. Climate, 19, 4914-4932.

—, — - and V. Krishnamurthy, 2008: An asymmetric mode of tropical Indian Ocean rainfall variability in boreal spring. J. Geophys. Res., 113, D05104, doi:10.1029/ 2007JD009316.

Xie, P., and P. A. Arkin, 1996: Analyses of global monthly precipitation using gauge observations, satellite estimates, and numerical model predictions. J. Climate, 9, 840-858.

Xie, S.-P., 2004: The shape of continents, air-sea interaction, and the rising branch of the Hadley circulation. The Hadley Circulation: Past, Present and Future, H. F. Diaz and R. S. Bradley, Eds., Kluwer Academic, 121-152.

_ model of relevance to the ITCZ in the eastern Pacific. Tellus, 46A, 340-350.

, H. Annamalai, F. A. Schott, and J. P. McCreary, 2002: Structure and mechanisms of South Indian Ocean climate variability. J. Climate, 15, 864-878.

, Q. Xie, D. Wang, and W. T. Liu, 2003: Summer upwelling in the South China Sea and its role in regional climate variations. J. Geophys. Res., 108, 3261, doi:10.1029/2003JC001867.

Yang, J., Q. Liu, S.-P. Xie, Z. Liu, and L. Wu, 2007: Impact of the Indian Ocean SST basin mode on the Asian summer monsoon. Geophys. Res. Lett., 34, L02708, doi:10.1029/ 2006GL028571.

Yoo, S.-H., S. Yang, and C.-H. Ho, 2006: Variability of the Indian Ocean sea surface temperature and its impacts on AsianAustralian monsoon climate. J. Geophys. Res., 111, D03108, doi:10.1029/2005JD006001.

Yulaeva, E., and J. M. Wallace, 1994: The signature of ENSO in global temperature and precipitation fields derived from the microwave sounding unit. J. Climate, 7, 17191736 . 